\title{
Detecting Superior Mutual Fund Managers: Evidence from Copycats
}

\author{
Blake Phillips \\ School of Accounting and Finance, University of Waterloo \\ Kuntara Pukthuanthong \\ Trulaske College of Business, University of Missouri \\ P. Raghavendra Rau* \\ University of Cambridge \\ Review of Asset Pricing Studies, forthcoming
}

\begin{abstract}
We examine the ex ante ability of investors to identify superior mutual fund managers among the investor set likely most able, and with the greatest incentive to do so, their rivals. Identifying actual copycat funds via comparisons of trading in consecutive periods, we find little evidence to suggest that managers are able to detect superior funds. Copycats select funds with high prior performance and investment inflows, and the performance of the target fund reverses following copying initiation. If superior managers exist, our results suggest that the source of skill lies in private information obtained by these managers. These results are consistent with information models indicating that private, but not public, information can be profitable. (JEL G02, G23)
\end{abstract}

\footnotetext{
* Phillips gratefully acknowledges financial support from the Social Sciences and Humanities Research Council of Canada and PricewaterhouseCoopers. We would like to thank Wayne Ferson, Avanidhar Subrahmanyam, and an anonymous referee for helpful comments. Send correspondence to Raghavendra Rau, University of Cambridge, Trumpington Street, Cambridge, CB2 1AG, telephone: 44 (1223) 761-079. E-mail: r.rau@jbs.cam.ac.uk.
} 
Despite nearly a half-century of academic research, starting with Jensen (1968), the literature has not been able to conclusively establish whether mutual fund managers have superior ability to generate excess returns above a risk-matched benchmark on an after-cost basis. For example, Fama and French (2010) show that equity mutual funds earned a negative 85-basis-point annual return on average, relative to the Carhart (1997) four-factor model. However, a number of recent studies have shown that some active equity managers appear to earn positive excess returns by actively rebalancing their portfolios. For example, Mamaysky, Spiegel, and Zhang (2008) use a Kalman filter model to track dynamic mutual factor loadings and show that some mutual fund managers time their trades and earn positive excess returns. Dyck, Lins, and Pomorski (2013) show active management outperforms passive management in emerging markets, suggesting that the value of active management depends on the efficiency of the underlying market. Cremers and Petajisto (2009) show that managers whose portfolio holdings differ the most from their benchmarks, a measure they term "active share," earn significant excess returns. Cohen, Polk, and Silli (2010) show that the best ideas of active managers (the largest holdings in their portfolio) tend to strongly outperform smaller positions in their portfolio.

While the "active share" literature argues that superior managers exist, the "smart money" literature provides mixed evidence on investor ability to identify these managers. For example, Gruber (1996) and Zheng (1999) report that funds that experience inflows have superior short-term future performance relative to funds that realize outflows. However, Sapp and Tiwari (2004) argue that this relation is explained by momentum in stock returns, and Lou (2012) shows that the smart-money effect can be fully explained by predictable flow-driven returns.

What remains uncertain is whether superior mutual fund managers can be identified ex ante. In this paper, we examine whether superior performers can be detected ex ante by the persons who are likely most able, and have the greatest incentive to do so, their rivals. Specifically, we analyze the behavior and performance of funds that choose to copy a rival fund as opposed to implementing their 
own investment strategies. We examine three issues: First, how does the number of copycat funds change over time? Second, does the target fund indeed outperform standard benchmarks after being selected? Third, what is the source of the superior fund manager skill? Both the propensity of funds to use copycat strategies and the subsequent performance of the target funds serve as proxies for fund manager perceptions of the viability of such a strategy and their ex ante ability to detect superior fund managers.

What kinds of funds are most likely to copy other funds? We first note that the prior literature has typically defined managerial skill in terms of the manager's ability to pick superior portfolios (or to set timely asset allocation strategies). Copycatting involves a different type of skill. Practical implementation of a copycat strategy requires little skill, with the process being akin to running an index fund. Copycat skill lies not only in identifying a superior manager, but in identifying a superior manager whose trades remain informative regarding future returns following the lag imposed by disclosure timing. In other words, the source of copycat skill lies more in the ability to obtain private information on the stock-picking skills of other managers and persistence in the informativeness of those managers' positions over time.

Our copycat identification strategy is based on the timing of public disclosure of mutual fund holdings and focuses on the ex post identification of copycat funds after they have successfully replicated the target fund. ${ }^{1}$ As the copycat fund manager observes the holdings of the target fund with a one-period delay, we compare the change in portfolio weights in quarter or semiannual period $t$ for fund $x$ to resultant changes in portfolio weights in period $t+1$ for fund $y$ for all possible portfolio pairs drawn from the universe of U.S. domestic, actively managed mutual funds between 1991 and 2013. We label a fund a copycat if the change in portfolio weights in two or more consecutive periods matches by

\footnotetext{
${ }^{1}$ Copycat behavior passes through three phases: (i) the pre-copying phase, (ii) the equalization phase, and (iii) the copying phase. During the equalization phase, the copycat fund divests non-matching holdings and gradually replicates the target portfolio. Our identification strategy focuses on the copying phase, as in this phase, the trades between the copycat and target match nearly perfectly making identification most feasible. We discuss the identification strategy in more detail in Section 2.
} 
at least $75 \%$. To illustrate our method, consider two funds, $X$ and $Y$ (where fund $X$ is the potential copycat), that for simplicity, allocate their entire portfolio equally to only two firms, Apple and Microsoft. Thus, their portfolios are identical in period 1 with a 50\% weight on each company. In period 2, fund $Y$ shifts $5 \%$ of its portfolio weight from Apple to IBM. In period 3, fund $X$ shifts $10 \%$ weight from Apple to IBM.

\begin{tabular}{|c|c|c|c|c|c|c|c|}
\hline \multirow[b]{2}{*}{ Fund } & \multicolumn{2}{|c|}{$\begin{array}{l}\text { Period 1Weights } \\
(\%)\end{array}$} & \multirow{2}{*}{$\begin{array}{l}\text { Period } 2 \\
\text { Weights (\%) } \\
\text { Y }\end{array}$} & \multirow{2}{*}{$\begin{array}{l}\text { Period } 3 \\
\text { Weights }(\%) \\
X\end{array}$} & \multicolumn{2}{|c|}{$\Delta$ Weight (\%) } & \multirow[t]{2}{*}{$\begin{array}{l}\text { Difference in } \Delta \\
\text { Weight }(\%)\end{array}$} \\
\hline & $\mathrm{X}$ & $\mathrm{Y}$ & & & $\mathrm{X}$ & $\mathrm{Y}$ & \\
\hline Apple & 50 & 50 & 45 & 40 & -10 & -5 & 5 \\
\hline Microsoft & 50 & 50 & 50 & 50 & 0 & 0 & 0 \\
\hline IBM & 0 & 0 & 5 & 10 & 10 & 5 & 5 \\
\hline
\end{tabular}

In this example, only $50 \%$ of the trades match $(5 \%$ portfolio weight adjustment matched of a total of $10 \%$ of the portfolio weight adjusted by fund $X) .^{2}$ In our copycat analysis, we use consecutively more stringent criteria to identify copycats, requiring trades to match in adjacent periods by $80 \%, 85 \%$, and 90\%. Our results are qualitatively unchanged.

The prevalence of portfolio copying has received little attention. The literature finds, at best, indirect evidence that copying behavior matters. For example, Agarwal, Mullally, Tang, and Yang (2012) find that the liquidity of the stocks held by mutual funds increased after portfolio mimicking became easier following the 2004 frequency increase in mandatory holdings disclosure. Shive and Yun (2013) find that front-running of predictable flow-induced trading of mutual funds by hedge funds increased after 2004. Parida and Teo (2011) find that outperformance by funds with high abnormal returns in the past year drops by 17-20 basis points (bps) per month after 2004, which they attribute to front-running by follower funds. Frank, Poterba, Shackelford, and Shoven (2004) and Verbeek and Wang (2013) construct hypothetical copycat portfolios using semiannual and quarterly portfolio disclosures and show theoretically that copying past winning funds could generate returns in excess of

\footnotetext{
${ }^{2}$ For simplicity, we illustrate the example using whole numbers. For the actual calculation, we retain four significant digits in each stock weight (expressed as a decimal), and the final sum of the matching percentage is rounded to the closest two significant digits, for purpose of comparison to the copycat cutoff value. 
average fund performance. Similarly, Pomorski (2009) reports that funds that mimic previous winners by herding realize three- and four-factor alphas of $0.35 \%$ per month. To our knowledge, we are the first to use portfolio holdings to identify actual copycat funds, documenting which funds they choose to copy, and the performance implications for both the copycat and target fund.

A concern with our identification strategy is that the apparent mimicking behavior we document could also arise from managers jointly reacting to the same information signals regarding asset value. In other words, our results could just be attributable to managers herding on the same stocks simultaneously or with a lag. Both institutional investors and mutual fund managers have been shown to herd. For example, Sias (2004) hypothesizes that institutional investors follow each other into the same securities and infer information from each other's trades. Similarly, Brown, Wei, and Wermers (2014) show that mutual fund managers herd into stocks with consensus sell-side analyst upgrades and herd out of stocks with consensus downgrades.

Our copycat measure is different from herding measures commonly utilized in the literature, and we argue that it is inherently more stringent. For example, Sias (2004) and Lakonishok, Shleifer, and Vishny (1992) quantify herding based on the imbalance of institutional investor buyers and sellers in the same or consecutive periods. In contrast, our measure captures perfectly aligned trades as a proportion of total net assets (TNA) by two funds in a minimum of two consecutive periods, as opposed to measuring the aggregate trading imbalance among all equity funds. By relating target fund trades in period $t$ to the trades of potential copycat funds in period $t+1$, we inherently control for simultaneous reactions to information flows. However, it is possible that we are falsely attributing copycat behavior to managers who react to the same information source as target fund managers but with a lag.

We validate the copycat measure in two ways. First, in ordinary least square (OLS) and vector autoregressive (VAR) regression models, we relate the change in holdings of stock $i$ by the copycat 
fund to the lagged trades of the target fund plus contemporaneous and lagged proxies for information arrival (stock return and turnover). The relation between copycat and target fund trades remains highly significant in the presence of information flow proxies and, in particular, remains significant when the Sias (2004) herding measure is added to the specification. When the regression specification is reversed, copycat trading has no explanatory power for target fund trading. In other words, herding and simultaneous or delayed reactions to information flows do not appear to explain the trades of copycat funds, which nearly perfectly mimic the target fund.

Unfortunately, our results are still subject to an omitted variable problem, as we are unable to conclusively control for all sources of information arrival. Hence, in our second robustness exercise, we draw on two natural experiments in our sample period that should impact the ability of managers to copy superior funds. We hypothesize that when choosing target funds, copycats face two primary concerns. First, they need to find funds that they believe have an edge (superior funds). Second, they need to have data to copy these strategies (quick disclosure).

The two natural experiments we identify affect both these concerns. The first, Regulation Fair Disclosure (Reg FD), adopted by the Securities and Exchange Commission (SEC) in August 2000, states that managers cannot privately disclose material information to financial analysts (Release No. 33-7881). We argue that this regulation made detection of superior funds more difficult as it reduced the potential for alpha generation through the informational advantage enjoyed by larger fund families with preferential relationships with investment banks. For example, Bhojraj, Cho, and Yehuda (2012) show that the relation between mutual fund family size and performance is positive prior to Reg FD and reverses in the post-regulatory period. They argue that the superior performance of large fund families arose due to selective disclosure of material, non-public information by investment banks, and not superior stock-picking skill. 
The second natural experiment occurred in 2004 when the SEC amended the Investment Company Act of 1940, doubling the frequency with which mutual funds were required to disclose portfolio holdings from twice to four times per annum. Proponents of the change argued that investors would be better able to monitor funds to ensure they were investing according to their stated investment objectives and detect various types of portfolio manipulation. ${ }^{3}$ Mutual fund managers raised concerns that increased disclosure created greater opportunity for copycats, free-riders, and front-runners to the detriment of funds that expend resources in research and/or have superior stock-picking ability. The prior literature (see, for example, Parida and Teo 2011 or Verbeek and Wang 2013) argues that the 2004 doubling of disclosure frequency impacted mutual fund mimicking behavior and theoretical success.

These two experiments imply that prior to 1999, copycats traded off limited information disclosure (portfolio information was disclosed every six months) against the higher potential for alpha. After Reg FD, the source of alpha (private information) was reduced, but the level of disclosure stayed the same. After 2004, the change in the disclosure requirements increased the ease of copying, but the level of private information stayed limited. Hence, if investors are indeed reacting to the same information with a lag (but not solely to the superior fund's trades), using our copycat identification strategy, there should be a reduction in apparent copycat behavior after the level of information was reduced in 1999. However, there should be no pickup in apparent copycat behavior after the 2004 reform since the level of information disclosure was not affected. In contrast, if our strategy is indeed successful in identifying managers who copy other fund managers, we should observe a drop in copycat behavior after 1999 and an increase after 2004.

The latter is precisely what we find. We find that portfolio mimicking is most prevalent in the pre-Reg FD period (1991-1999) when approximately fifty (median levels) funds annually appear to be

\footnotetext{
${ }^{3}$ See 17 CFR Parts 210, 239, et al. Shareholder Reports and Quarterly Portfolio Disclosure of Registered Management Investment Companies; Final Rule, March 9, 2004.
} 
implementing a copycat strategy. The number of copycat funds decreases markedly between 2000 and 2001, dropping to a median value of eleven funds over the 2000-2003 period, but doubles again following the increase in required portfolio disclosure frequency (2004-2013) to a median value of nineteen funds annually.

The change in the number of copycats is obscured to a degree by the rapid growth in the mutual fund industry during our sample period (a five-fold increase in actively managed equity funds). We note that the reduction in the percentage of the population implementing a copycat strategy in part reflects that few of the funds initiated in this time frame started with a copycat strategy. Although the regulatory environment and disclosure frequency clearly impacted the number of copycat funds, across our entire sample the number of copycats is typically small relative to the universe of active mutual funds, suggesting that managers do not believe that copycatting is an effective strategy.

What kinds of funds copy other funds? As noted above, if fund managers were indeed able to ex ante identify superior fund managers based on private information, we would expect there to be little relation between the pre-copying financial performance of copycat funds and their propensity to engage in this strategy. In addition, because copycats are identifying superior managers ahead of the general public, it is not necessary that target funds outperform their benchmarks before the initiation of copycat behavior, but they should outperform their benchmarks after copying is initiated. Therefore, we examine the characteristics of both copycat and target funds, focusing on Lipper objective-adjusted values at the end of the year in which copycats complete portfolio equalization and commence the copycat phase.

We find that copycat funds are typically smaller than their targets, belong to smaller fund families, and are characterized by net asset outflows, high flow volatility, weak prior performance, high expenses, and high portfolio tracking error. In short, copycat funds are typically distressed funds that appear to turn to mimicking behavior to reverse current performance and investor redemption trends. In 
contrast, target funds are typically strong past performers that have experienced strong investment inflows at both the fund and family levels and are highly ranked by analysts such as Morningstar. Copycats appear to copy larger funds that belong to larger fund families and have lower portfolio tracking error, rendering them more easily copied. Copycat funds are more likely to initiate copying in periods of financial market uncertainty (proxied by the VIX index) and during periods of high aggregate inflows to equity funds. Consistent with our results on the low unconditional likelihood of funds adopting a copycat strategy, these results suggest that distressed funds with few other options are typically the only funds to adopt such a strategy. They also suggest that publicly available information on target fund returns and flows are significant determinants of the likelihood of being copied.

We next find limited evidence that copycat funds have the ability to detect superior funds. Examining the performance of both the target and copycat funds in the year after mimicking initiates, we show that target funds realize four-factor alphas of approximately $2.5 \%$ in the year following the start of the copying phase. This is an average improvement of approximately $2.0 \%$ over the prior year. Copycats realize similar or greater performance improvements over the same period but fail to fully capture target fund performance (average four-factor alphas are approximately $-0.6 \%$ ). Prima facie, this appears to suggest that copycat funds can indeed identify superior fund managers, though they cannot copy them effectively. However, over a longer horizon (up to four years after the initiation of copying), the performances of both the target and copycat funds rapidly decay to averages of $-3.2 \%$ and $0.4 \%$ for the copycat and target funds, respectively. It appears that copycat funds use prior performance as a primary criterion when selecting a fund to copy, and this superior performance is sustained in the short term. However, they are unable to identify funds with persistent superior performance. Additionally, the performance gap between the target and copycat fund widens over time, suggesting that copycat ability to replicate the performance of the target fund similarly decays. 
What explains the contrast between the short- and long-term returns earned by the target and copycat funds? Our analysis of the determinants of which funds are likely to be copied points to a momentum-based explanation. Target funds are typically strong past performers that have earned high asset inflows, both at the fund and family levels over the prior six months. These characteristics are also consistent with high investor sentiment funds that have experienced flow-induced price pressure. For example, Frazzini and Lamont (2008) use mutual fund flow as a measure of investor sentiment and find that high sentiment predicts low future returns.

What determines copycat success? To answer this question, we investigate the determinants of the performance gap between the target and copycat fund and the ability of the copycat fund to divert flow from the target fund. The performance gap between target and copycat funds is smaller (i.e., copycat performance is stronger) when the target fund charges higher expenses, is smaller, has lower past performance, trades less, has a lower tracking error, and holds more assets. Similar factors drive the flow gap between the copycat and target funds. If the copied fund charges higher management expenses or is larger, the copycat fund tends to capture a greater proportion of flow. The loss of flow to the copycat is reduced by fund- and family-level advertising, and larger performance and Morningstar Rating gaps between the target and copycat funds. Comparing actual and counterfactual flow for the target fund suggests that increases in flow to the copycat are realized at the expense of the target, but the relative magnitude of the captured flow is small.

In summary, we find little evidence that mutual fund managers are able to detect superior managers among their peers. A relatively small number of funds employ a mimicking strategy, an entirely legal strategy that would likely be implemented more broadly if effective. Copycatting appears to be an act of desperation implemented by funds in distress or, at a minimum, is used as a strategy to reverse negative recent performance and investor perceptions. Copycats are successful in the sense that they are able to improve their current performance. The funds they copy do not appear to earn 
persistent excess returns in the long term, suggesting that copycat funds simply copy funds that earn high short-term past returns.

We note that our results do not imply that superior mutual fund managers do not exist, just that ex ante identification, if possible, is extremely difficult and few investors possess this ability. If superior fund managers do exist, our results are consistent with the hypothesis that they exploit shortlived information, information that becomes stale in less than a quarter. In addition, our results on the drop in copycatting behavior after the passage of Reg FD in 2000 are consistent with the hypothesis that other managers believe that the source of stock-picking skill lies in private information obtained by these managers. Finally, the poor performance by the copycat funds provides evidence consistent with information models indicating that private information, but not publicly available information, can be profitable. ${ }^{4}$

Our findings have implications for the policy debate regarding portfolio disclosure frequency. As discussed, opponents to the increase in holdings disclosure frequency mandated by the SEC in 2004 pointed to a likely increase in copycat free-riding. Our analysis suggests that, while mandated increases in disclosure frequency did increase the number of copycat funds, their overall frequency remains small. We also find little evidence to suggest that copycat success is significant or that it has varied significantly over time. Overall, our results suggest that the costs of copycats are likely to be small. However, we also note that our copycat measure is inherently stringent and is unable to detect funds that are employing partial copycat or mixed copycat strategies (duplicating multiple funds at once). Thus, our results potentially understate the costs and effects of copycat behavior, although we have no reason to believe that the results for partial or mixed copycats will not be similar to those we obtain for pure copycats.

\footnotetext{
${ }^{4}$ See, for example, Garcia and Vanden (2009), Admati and Pfleiderer (1986, 1988, 1990) and Biais and Germain (2002) for discussion of information models and the decisions of financial intermediaries to trade on private information or sell it to clients through a managed fund. 


\section{Data}

We obtain mutual fund return and characteristic data from the Center for Research in Security Prices (CRSP) mutual fund database. We restrict our sample to actively managed, domestic mutual funds and apply the additional restriction that the fund must report monthly frequency returns and TNA, restricting our sample to the period of 1991-2013. ${ }^{5}$ Multiple classes of the same fund are aggregated using a TNA-weighted approach. Portfolio holdings data is similarly obtained from CRSP for the period of 2004-2013. For the period of 1991-2003, we obtain holdings data from Thomson Reuters, which we link to CRSP using the MFLINKS file developed by Wermers (2000). We supplement the fund characteristic data in CRSP with mutual fund advertising data from Kantar Media (KM) as used in Phillips, Pukthuanthong, and Rau (forthcoming). The KM advertising dataset summarizes advertising spending at the family and fund levels between 2005 and 2011 . We provide greater detail on this dataset in Online Appendix A.

\section{Copycat Fund Identification}

As previously discussed, there are three phases of copycat behavior:(i) the pre-copying phase, during which the target and copycat funds employ unique strategies and have relatively low portfolio commonality, (ii) the equalization phase, during which the copycat selects the target fund and seeks to replicate its portfolio while divesting non-common holdings, and (iii) the copying phase, during which the trades of the copycat closely mirror the trades of the target fund, but with a delay due to disclosure timing. Our identification strategy focuses on the copying phase, as it is this phase of copycat behavior that is most identifiable and can most clearly be differentiated from coincidentally matching trades. During the other phases of copycat behavior, commonalities in portfolio holdings and trades are

\footnotetext{
${ }^{5}$ To identify actively managed mutual funds, we use the list of actively managed funds from Petajisto (2013), available from Antti Petajisto's website, http://www.petajisto.net/data.html. 
typically low. Thus, we are identifying copycats ex post, after they have effectively duplicated the target fund portfolio.

To identify copycat funds, we compare the change in portfolio holding weights (i.e., trades) between all possible fund pairs in adjacent periods (excluding fund pairs from the same family), considering 4,117 unique portfolios in total. Specifically, if fund $X$ is copying and has replicated the portfolio of fund $Y$, we would expect that, following portfolio disclosure by fund $Y$ in period $t$, we would observe duplicate trades by fund $X$ in period $t+1$. Thus, comparing the change in portfolio holding weights for fund $X$ in period $t+1$ to fund $Y$ in period $t$, we label fund $X$ a copycat fund if the change in weights meets a minimum value of commonality in two or more consecutive periods. An added benefit of this strategy is that it inherently mitigates against mistaking simultaneous, common reactions to information signals as copycat behavior. For example, managers jointly observing the same information may react in a similar manner, giving a false perception of copying. However, such joint reactions should occur in the same period and not with a period delay on the part of one manager, let alone with the delay persisting for two or more periods. We control for the potential bias of lagged common reactions to jointly observed information signals more formally further in the paper.

The mutual fund holding data reported by CRSP and Thomson Reuters is obtained from forms N-CSR and N-Q filed with the SEC as required under Sections 13(a) or 15(d) of the 1934 Securities and Exchange Act or under Section 30(b)(2) of the Investment Company Act of 1940. Mutual funds are required to file form N-CSR within ten days of the transmission of any annual or semiannual report that is required to be transmitted to stockholders. Form N-Q is to be filed not later than sixty days after the close of the first and third quarters of each fiscal year. Thus Forms N-Q and N-CSR jointly result in a quarterly disclosure of portfolio holdings in the 2004-2013 period. By contrasting adjacent periods, our copycat identification method controls for potential delays in Form N-Q filing. For example, if a copied fund was to delay filing Form N-Q by sixty days, the copycat fund would observe the holdings 
schedule shortly thereafter and replicate the trades of the target fund. The duplicate trades would then appear in the holdings disclosure of the copycat in the following quarter. In addition, if the apparent copying behavior is caused not by information but, for example, by a change in benchmark, which funds react to with a delay, the lagged change in portfolio holdings would not persist for the same fund for two consecutive periods as we require.

To reduce the influence of nonreported assets, such as cash and non-equity security holdings, on the identification of copycat funds, we utilize portfolio asset weights calculated as a percentage of reported assets, not TNA:

$$
w_{i, j, t}=\frac{M C_{i, j, t}}{\sum_{i} M C_{j, t}}
$$

where $w_{i, j, t}$ is the portfolio weight of asset $i$ in portfolio $j$ in period $t$ and $M C$ is market capitalization. Beyond the influence of nonreported assets on the matching process, we also recognize that differences may exist between funds due to other factors. First, differences in fund covenants between the target and the copied fund may restrict perfect copying. Second, the holdings data we utilize are imperfect, short positions are not disclosed, and funds are not required to disclose holdings of individual assets worth less than $\$ 200,000$ or 10,000 shares.

To account for these issues, we form four samples, varying the minimum match in trading activity between funds in adjacent periods from $75 \%$ to $90 \%$. As in the example in the introduction, the percentage of trades matched is measured as the sum of the difference in the change in the weights across all stocks in the fund pair portfolios, divided by 2 (as a mismatch in one trade, by construction, means a second trade will not match) and expressed as a proportion of total weight adjusted by the copycat fund. A potential concern with this approach is the treatment of missing values. If neither fund traded over the periods, we would compute a perfect trading match percentage. However, it is highly uncommon for a fund to not trade over a three- or six-month period. In addition, as we examine two consecutive periods, only an absence of trading for six months or a year (depending on the timeframe) 
would reflect a perfect match due to inactivity. As a further filter for potential inactivity bias, we also compare the total holdings of the funds and require a match of at least $70 \%$ for a pair to be included in the copycat sample.

Theoretically, it is not clear what is the "correct" cutoff to distinguish between copycat behavior and coincidentally common trades. We argue that coincidental consecutive matches of trading activity in adjacent quarters of $75 \%$ are highly improbable and a match of $90 \%$ almost unquestionably reflects copycat behavior, with the former cutoff being potentially too lax and the latter perhaps too stringent. Thus, we utilize a cutoff of $75 \%$ (rounded to the nearest whole integer) for the models reported in the paper and undertake robustness tests of all models, varying the matching criteria in 5\% increments. Our results are largely consistent across the various cutoffs from $75 \%$ to $90 \%$. In addition, we note that our methodology results in an extremely stringent measure. Just as a match of zero trading might appear as a perfect match, a relatively small misalignment of two funds trading a small weight in two different stocks would reflect a perfect mismatch. The likelihood of a false positive is extremely small. For example, in our sample, on average, funds change position weights for 72 stocks in each period. ${ }^{6}$ For a random perfect match in trades to occur, the manager must thus select the exact same stocks to trade from a portfolio consisting, on average, of hundreds of assets and hundreds of additional assets not held but which meet the fund investment objective. Further, after selecting the same 72 stocks to trade, the manager must correspondingly choose to vary the weights by the same amount for each stock within the range of a $0-100.00 \%$ weight. As previously suggested, the chance of such an occurrence, or even a $75 \%$ match, via random, independent draws from the set of available investment assets is infinitesimal. Of course, asset selection by mutual funds is not random. Managers observe common information signals such as media coverage, corporate disclosures, and analyst coverage and may also infer

\footnotetext{
${ }^{6}$ This value is based on the change in position weights between end of period disclosures and does not reflect round-trip trades completed within the period. 
information from the trades of other funds. Thus, we validate our selection process for the influence of these factors and discuss the tests in more detail below.

Though focusing on the copying phase of copycat behavior and requiring matching trades of 75--90\% has the benefit of providing a clear copycat identification strategy, it is not without its limitations. There likely exists a spectrum of copycat behavior, ranging from outright portfolio duplication at one end of the spectrum (pure copycats, the focus of our analysis) to partial duplication, with only a portion of TNA at the other end of the spectrum. Funds may also elect to copy multiple funds simultaneously. Since clear differentiation of partial or mixed copycat strategies from coincidentally matching trades is almost impossible if copycats copy only a small proportion of holdings, we focus on funds implementing pure copycat strategies. It is likely that the results we document for pure copycats are extendable to funds that copy several funds or copy with a portion of assets under management (i.e., performance and copying ability are likely similar for other copycat types). More importantly, the managers of pure copycat funds are likely to have the greatest faith in their target fund selection ability. Hence the results for this group potentially represent the upper bound on copycat outcomes.

Table 1 summarizes the copycat fund sample. As previously discussed, we utilize two changes to the regulatory environment that likely impacted the funds' ability to mimic the trades of a rival:(i) prior to Reg FD (2000) and (ii) after the mandated change in portfolio disclosure frequency (2004). Hence, we partition the copycat fund summary statistics over the time intervals of 1991-1999, 20002003, and 2004-2013. Requiring that the copycat and target fund belong to different fund families and using a portfolio weight change minimum matching criteria of $75 \%$ in at least two quarters, we identify 493 copycat pairs over the interval of 1991-1999, related to 292 unique copied funds. On average, copying occurs for 7.2 quarters (standard deviation 5.4 quarters), and trades in adjacent periods match by $79 \%$, resulting in an $83 \%$ match in portfolio weights during the copying period. Tightening the 
matching criteria to a greater-than-85\% alignment in portfolio weight changes reduces the sample to 278 unique copycat funds and increases the percentage of trades in adjacent periods to $91 \%$ and portfolio weights in common to $90 \%$. As is reflected by the larger number of copycat than target funds, some funds are copied by multiple funds. However, some copycat funds also copy different funds in different periods, and the difference in total copycat and target funds reflects the joint influence of these factors. Summary statistics for the other two time intervals reflect similar trends, although the number of copycat fund initiations decreases in part due to the length of the interval and time-series trends in copycat behavior, which we explore in greater detail below.

\subsection{Copycat pair validation}

A concern when utilizing portfolio holdings to identify copycat funds is the potential that managers are simply reacting in unison (or with a delay) to commonly observed information and thus erroneously appear to have mimicking trade patterns. To an extent, our method controls for this potential misidentification by contrasting two or more adjacent periods of portfolio disclosure. However, it is plausible that managers react to the same information signals but with a delay. Autocorrelation in trades across multiple periods might also confound clean identification of copying behavior.

To control for these potential misidentification issues, we use three tests. First, as we note in the introduction, there were two regulatory changes in 1999 and 2004 that acted as natural experiments, varying the availability of superior information and the ease of copying. In 1991-1999, before the introduction of Reg FD, there were fifty active copycat funds (median levels) annually, with a maximum of ninety-five active copycats in 1996 (based on a trade commonality cutoff of 75\%). This compares with a median of eleven funds in the 2000-2003 period (after the introduction of Reg FD and prior to the mandated increase in portfolio disclosure) and twenty-five funds in the 2004-2013 period after the increase in disclosure frequency. While the percentage of the population utilizing a mimicking 
strategy follows a similar trend, the trend is obscured by rapid growth in the fund industry in our sample, which reduces the relative percentage of copycats in the later part of the sample. The percentage trends suggest that funds are rarely initiated with a copycat strategy; copycatting starts when the intended strategy becomes ineffective.

Second, in OLS regressions, we relate the change in the portfolio weight of the copycat fund for stock $i$ in period $t$ to stock-level information proxies for stock $i$ in period $t$ and $t-1$ plus the change in the portfolio weight for stock $i$ for the target fund in period $t-1$. It should be noted that the validation value of this model is not to confirm that a relation exists between the trades of the target and the lagged trades of the copycat. As this relation is the foundation of the selection criteria, this relation is present by construction and is verified in Model (1) of Table 2 (Panel 1). The objective of this model is to isolate the source of commonality in trades between the copycat and target fund, or more precisely, to rule out common reaction to information signals as the source. Successively, in Models (2) and (4), we add stock returns and turnover over several horizons as proxies for information flows. If common reaction to information is the cause of the commonality in trading, we expect the significance and magnitude of the $\Delta$ Weight target fund coefficient to decrease as information flow proxies are added to the model. Focusing on Model (4), which simultaneously includes all of the information proxies, the magnitude and significance of the $\Delta$ Weight target fund coefficient is actually greater (but not statistically different) than the base specification (Model 1), suggesting that common reaction to information flows is not the source of commonality of trades. Additionally, Sias (2004) argues that mutual fund managers infer information from the trades of other funds. Thus, the institutional investor herding measure from equation (4) in Sias (2004) is included as an additional information flow proxy in Models (6)-(9): 


$$
\begin{gathered}
\operatorname{Herding}_{t}=\rho\left(\Delta_{k, t}, \Delta_{k, t-1}\right)= \\
{\left[\frac{1}{(K-1) \sigma\left(\operatorname{Raw}_{K, t}\right) \sigma\left(\operatorname{Raw}_{K, t-1}\right)}\right] \times \sum_{k=1}^{K}\left[\sum_{n=1}^{N_{k, t}} \frac{\left(D_{n, k, t}-\overline{\operatorname{Raw}_{t}}\right)\left(D_{n, k, t-1}-\overline{\operatorname{Raw}_{t-1}}\right)}{N_{k, t} N_{k, t-1}}\right]} \\
+\left[\frac{1}{(K-1) \sigma\left(\operatorname{Raw}_{K, t}\right) \sigma\left(\operatorname{Raw}_{K, t-1}\right)}\right] \times \sum_{k=1}^{K}\left[\sum_{n=1}^{N_{k, t}} \sum_{m=1, m \neq n}^{N_{k, t-1}} \frac{\left(D_{n, k, t}-\overline{\operatorname{Raw} \Delta_{t}}\right)\left(D_{m, k, t-1}-\overline{\operatorname{Raw}_{t-1}}\right)}{N_{k, t} N_{k, t-1}}\right]
\end{gathered}
$$

where $\rho\left(\Delta_{K, t}, \Delta_{K, t-1}\right)$ is the cross-sectional correlation between the ratio of buyers and sellers in adjacent periods calculated from $N$ investors across $K$ securities, $\operatorname{Raw} \Delta_{K, t}$ is the raw fraction of institutions buying security $k$ during quarter $t$, and $\overline{\operatorname{Raw}_{t}}$ is the cross-sectional average (across $K$ securities) raw fraction of institutions buying in quarter $t . N_{k, t}$ is the number of investors trading in stock $k$ in period $t$ and $D_{n, k, t}$ is an indicator variable equal to 1 if investor $n$ is a buyer of security $k$ in period $t . D_{m, k, t-1}$ is an indicator variable equal to 1 if trader $m(m \neq n)$ is a buyer (seller) of security $k$ in quarter $t-1$. Addition of the herding measure has no effect on our conclusions.

A potential concern with this model is that a relation between the trades of the copycat and the target fund was the foundation of the selection process for the sample. Thus, as an additional test, we replicate the model four quarters after selection to introduce a degree of separation between selection timing and the validation test. We find the same results in this alternative specification reported in Panel 3 of Table 2 in the Online Appendix. Importantly, the coefficients on the change of weight on the target fund do not get smaller when the information proxies are introduced in the alternative timing model.

Next, as an additional validation exercise, in Table 2, Panel 2, of the main paper, we replicate the regression using trades by the target fund as the dependent variable, which we relate to lagged copycat fund trades and the same information flow proxies. This model specification allows us to validate the directionality of the relation between copycat and target fund trades, ensuring that the copycat fund is indeed responding to target fund trades. In all model specifications, the relation 
between the change in target fund portfolio weights and lagged copycat fund weights is insignificant (average $t$-statistic 0.36 ), further validating our hypothesis that the copycat fund is responding to target fund trading activity and not vice versa.

We also undertake a series of robustness tests, reported in Panel 4 of Table 2 in Online Appendix B. First, we replicate Model (4) in Panel 1 utilizing a VAR model as opposed to OLS. ${ }^{7}$ Results between the VAR and OLS models are consistent. Importantly, drawing on $\chi^{2}$ model estimates from the VAR model, we find that the change in the portfolio weight of the target fund Granger causes the change in the portfolio weight of the copycat fund in the subsequent period.

Second, we draw on findings by Wermers (1999), who reports that herding behavior is more common for small and growth stocks. To further differentiate the behavior we document from herding behavior, we partition our sample by market capitalization and risk objectives based on Lipper management objective classifications. The copycat validation test result should be similar across partitions if copying (as opposed to herding) is motivating the behavior. In contrast to the herding behavior noted by Wermers, we find that copycat behavior is consistent across size and risk partitions. Specifically, the coefficients on the changes in portfolio weights of the target funds are not statistically different from each other.

\subsection{The equalization period}

In our third validation exercise for the copycat sample, we examine the equalization period of copycat behavior. If copycats are transitioning through the three previously described phases of copycat behavior, we expect low portfolio commonality in the pre-copying period, followed by a rapid increase in portfolio commonality over a reasonably short period, concluding with sustained high portfolio commonality. Figure 1 reports the average percentage of portfolio weights in common between the

\footnotetext{
${ }^{7} \mathrm{We}$ include one lag of the change in the weight of the copycat fund in the regression, determined based on Akaike's Information Criterion tests.
} 
target and copycat fund, in the two-year period preceding the date the copycat enters the sample. Thus, Figure 1 charts the pre-copying and equalization periods preceding the copying period. We focus on the 2004-2013 period as quarterly disclosures are available in this timeframe, allowing for sharper inferences regarding phase timing. ${ }^{8}$

Over the period of one to two years preceding copying, there is low portfolio commonality between the target and copycat fund, ranging from $0 \%$ to $14 \%$ for the eight and four quarters preceding the copying period. Between three and four quarters prior to the copying phase, portfolio commonality increases nearly fourfold, from $14 \%$ to $45 \%$, and over the following two quarters, it steadily increases to a level in excess of $70 \%$. This trend suggests a very rapid and deliberate increase in portfolio commonality consistent with copycat behavior. On average, the equalization phase lasts 3.3 quarters over the 2004-2013 period.

\section{Who Copies Whom?}

Our first battery of tests focuses on the determinants of copycat behavior. Which funds are likely to be targeted? If fund managers indeed have the ability to identify successful managers before the general public, target funds need not outperform in the past. However, they should outperform after being copied. In contrast, if copycats copy targets based on the same public information as general investors, funds that have been recently successful, and that are more easily copied, are most likely to be chosen.

We treat each instance of copying initiation as a unique observation (i.e., copying two different funds by the same copycat in different timeframes would be two observations). However, we find similar results if we exclude sequential copying events by the same copycat fund. As candidate fund characteristics, we consider prior performance, expenses, portfolio turnover, tracking error, size,

\footnotetext{
${ }^{8}$ We obtain highly similar but coarser results over the 1991-2003 period. 
investment flows, advertising expenditures, and Morningstar rating. The flow for fund $i$ in month $t$ is calculated as the percentage change in TNA while controlling for return $(R)$ effects:

$$
\text { Flow }_{i, t}=\frac{T N A_{i, t}-T N A_{i, t-1} \times\left(1+R_{i, t}\right)}{T N A_{i, t-1}}
$$

We measure fund performance as the return net of expenses, as well as net risk-adjusted returns utilizing the CAPM, the Fama-French three-factor model, and the Fama-French-Carhart four-factor model estimated over the twenty-four months preceding the commencement of copying as benchmarks. To measure how informative the fund portfolio disclosure is to the actual strategy followed by the fund, we follow Verbeek and Wang (2013) and measure the tracking error for fund $j$ as:

$$
T R_{j, t}=\sigma\left\langle\widetilde{R}_{j, t-s}-\sum_{i} \widetilde{w}_{i, t-2} \widetilde{R}_{t-s}^{b_{i, t-2}}\right\rangle, s=0,1, \ldots, 4
$$

where $\widetilde{R}_{j, t-s}$ is the realized monthly return to fund $j$ for each of the five months prior to the portfolio disclosure date $t, \widetilde{w}_{i, t-2}$ is the value weight for stock $i$ (disclosed at time $t$ ) two months before the disclosure date, and $\widetilde{R}_{t-s}^{b_{i, t-2}}$ is the month $t-s$ return of the style benchmark portfolio that is matched to stock $i$ at the end of month $t-2$. Equation (4) defines the tracking error of the mutual fund relative to a style benchmark five months before the disclosure date (three months before and two months after the snapshot date). The portfolio holdings disclosed at the end of each period both serve as an indication for a fund's investments in that period and also convey information of the fund's intended investment strategy in the coming period. If the portfolio disclosure is informative of the investment style the fund has maintained, the style benchmark returns should be highly correlated with the realized fund returns and thus generate a low tracking error. We utilize the style benchmarks and matching methodology as described in Daniel, Grinblatt, Titman, and Wermers (1997) and Wermers (2004), matching funds to style benchmarks across three dimensions: market capitalization, value-growth orientation, and 
momentum. ${ }^{9}$ As fund characteristics may vary systematically by management objective, we compute determinant variable values in excess of the mean value for all funds in the same management objective (objective-adjusted), based on Lipper management objective classification from CRSP. We reach the same conclusions if we use unadjusted values.

\subsection{Univariate analysis}

In Table 3, we report univariate statistics for the copycat and target funds for the period (quarter or semiannual period) in which the copying phase commences. As our advertising database ends in 2011, in this section, we focus on the period from 1991 to 2011. Across all three periods, target funds tend to be larger than their objective peers (on average, 155 million U.S. dollars [USD] TNA larger) and come from larger fund families. Target funds typically realize higher and less volatile flows as a proportion of TNA, both at the fund and family levels. On both an unadjusted and risk-adjusted basis, target funds significantly outperform their objective peers. On an annualized basis, target funds outperform copycats by $4.52 \%$ (six-month return difference) based on net returns and $2.90 \%$ based on risk-adjusted net returns (average across the three alphas from the risk-adjusted models in all periods). Loads and expenses tend to be marginally higher for target funds, which tend to trade less than other funds in the same objective (based on portfolio turnover). Finally, target funds tend to have lower portfolio tracking errors. They spend less on family-level advertising but spend more on fund-level advertising, in particular on advertising promoting strong past performance.

These target fund characteristics stand in stark contrast to the copycat characteristics. Copycat funds are smaller than their objective peers and belong to smaller fund families. Both risk-adjusted and unadjusted prior performance values are negative, and copycat funds experience abnormally low investment flows in the year preceding copycat initiation. Copycat funds typically charge lower

\footnotetext{
${ }^{9}$ The DGTW benchmarks are available at http://www.smith.umd.edu/faculty/rwermers/ftpsite/DGTW/coverpage.htm. $-23-$
} 
objective-adjusted expenses than the fund they choose to copy and spend significantly less on advertising than their objective peers.

In sum, Table 3 provides evidence broadly consistent with the hypotheses that fund managers do not have the ability to identify superior peers ex ante. Copycat behavior is not widespread, and copycats are typically below-average performers and have low fund flows, consistent with copying being employed by funds as an act of desperation. In contrast, target funds are typically top performers with a corresponding history of attracting abnormally high investor flows. Further, funds selected as targets for copying have characteristics that make them easier than the average fund to emulate. Specifically, they trade less than their objective peers and make more representative end-of-period portfolio disclosures.

As an additional test, we focus on copycats that change target funds. This focus allows us to further validate the previously discussed determinants of copycat behavior in a controlled event study setting. For example, copycats may want to mimic larger and more visible funds. Hence, if size is an important determinant of copycat behavior, copycats are likely to trade up when they switch the fund they are copying, switching to a relatively larger fund. Focusing on the 2004-2011 period, copycats switch targets 81 times in our sample (switches occur 74 and 69 times in the 1991-1999 and 20012003 periods, respectively). Panel 2 of Table 3 tabulated in the Online Appendix B reports comparative statistics for the original and new target fund. When copycat funds switch targets, they typically choose larger funds from larger families, both of which have realized higher abnormal flow in the prior six months. They also switch to funds with higher three- and four-factor alphas, funds with lower tracking errors, and funds that spend less on advertising. The remaining characteristics are not statistically different between the original and new target fund. These results are consistent across time intervals and are broadly consistent with the relations noted in Table 3 in the main paper. 


\subsection{Multivariate analysis}

We next examine the determinants of copycat behavior in a multivariate setting in Table 4 . We do this in part as a robustness exercise for Table 3, controlling for interdependence in fund characteristics that is not reflected in univariate differences. In addition, this analysis enables us to contrast target and copycat funds relative to the universe of actively managed funds (as opposed to across pair and within objective comparisons). The decision to commence copying is modeled using a multivariate logit model with the dependent variable set to 1 in the period of copying initiation, and the fund being removed from the sample thereafter. Copycat and target fund characteristics are considered in separate models. We use the same determinant variables as in Table 3, with the exception of excluding overlapping performance and flow measures to avoid collinearity issues. To this set of determinant variables, we add economic market state proxies, specifically aggregate flow to all funds in the sample, the return to the S\&P 500 index and the VIX volatility index. We also add indicator variables for 2000-2003 and 2004-2010, coinciding with the previously discussed regulatory changes, which we hypothesize affect copycat likelihood. Standardized coefficient values are reported, with associated $t$-statistics calculated from standard errors clustered by fund. In addition, each model includes year/quarter or year/six-month period (as appropriate) fixed effects.

Table 4 in the main paper presents estimates for the full sample, and Panel 2 (tabulated in the Online Appendix B) presents separate sub-period analyses. Since the univariate (Table 3) and multivariate results are highly similar, in the interest of brevity, we refrain from reiterating previously discussed results and focus instead on inferences of the relative importance of determinant characteristics and the newly included state variables.

Focusing first on the state variables for the full sample in Table 4, copycat behavior appears more likely to commence following higher inflows into equity funds (the average $t$-statistic across the four models is 2.39). Ferson and Warther (1996), Ferson and Kim (2012), and Chalmers, Kaul, and 
Phillips (2013) show that investors collectively move flows in and out of equity funds in anticipation of shifts in economic conditions. Our results are consistent with copycat funds commencing mimicking in periods of inflows into the equity fund market, when investors are making broad reallocations and flow is relatively attainable. Initiation of copying also appears more likely when the VIX index is high, consistent with managers resorting to mimicking when asset values are more uncertain and implementation of a successful management strategy is more difficult.

Focusing next on the relative importance of the determinant variables in predicting the likelihood of being a target fund, the dominant variable is fund flow, followed by fund and family size, and prior performance. Copycats also tend to favor funds with lower tracking errors and higher family flow. The other variables are not significant predictors of copying likelihood. The dominant predictor of initiation of copycat behavior is similarly family size, followed by fund size, flows, and past performance, but in the opposite directionality. Copycat funds are typically smaller, from smaller fund families, and are characterized by weak past performance and low or negative fund flows.

Examining the time-series trends in copycat likelihood, both the period indicators are negative and significant, suggesting that copycat behavior initiation likelihood is lower in both the 2000-2003 and 2004-2010 periods, relative to the 1991-1999 period. The difference in copycat behavior initiation likelihood is statistically significant between the 2000-2003 and 2004-2010 periods ( $t$-statistic 3.68). Thus, copycat behavior is most likely in the 1991-1999 period preceding establishment of Reg FD. Copycat initiations are least likely in the 2000-2003 period, post-Reg FD but before the mandated increase in disclosure frequency, becoming more likely when the required portfolio disclosure frequency increased to quarterly.

In the Online Appendix B, Panel 2 of Table 4 shows similar results in each of the three subperiods. Thus, while the number of funds employing copycat strategies dropped by nearly half after establishment of Reg FD, the determinants of copycat behavior and target selection remained constant. 
Focusing on the 2004-2013 period for which additional variables are available, we find that advertising spending and Morningstar rating are incremental positive predictors of copying likelihood and the size of the coefficients ranks these variables as among the dominant predictors. Correspondingly, we find these factors to be predictive of copycat likelihood, although the relation reverses for Morningstar ratings. Copycats tend to have lower Morningstar Ratings but advertise more heavily, perhaps attempting to compensate for recent investment outflows.

\subsection{Robustness analysis}

To validate the multivariate determinant analysis, we implement a placebo test to provide confidence that the documented relations arise due to the selection process of copycat funds and not due to random association or endogenous relations. The matched placebo copycat sample is constructed based on high portfolio commonality but with a corresponding absence of commonality in lagged trades. Specifically, a placebo copycat is selected to match each target fund requiring portfolio holdings to match by at least $80 \%$ in period $t$, but for which trades by the target fund in period $t$ match those of the placebo copycat in period $t+1$ by less than $10 \%$. We select $80 \%$ as the portfolio commonality requirement because this is the average level of portfolio commonality in the copycat sample. However, we obtain similar results if cutoffs of $60 \%$ or $40 \%$ are alternatively used. The placebo copycats in this sample have attained high portfolio commonality with the target fund via some other mechanism than mimicking. For example, they could both be responding similarly and simultaneously to the same information signals or be both independently implementing closet indexing strategies copying the same benchmark.

The placebo copycat regression results are reported in the Online Appendix B in Panel 3 of Table 4. We report results only for the copycat model because the target funds are the same between the test and placebo samples. We do not expect an absence of significant relations in the placebo models, just 
different relations. The portfolio commonality we have selected in the placebo sample is not likely random and, as discussed, potentially arises due to closet indexing or some other behavior. Contrasting the placebo results with Table 4 in the main paper, fund size, fund flow, family size, tracking error, aggregate flow, and performance are no longer significant determinants of copycat likelihood (based on alpha of 0.05). In particular, the sign on aggregate flow and tracking error reverses. In further contrast, total load and turnover become significant predictors of being a placebo copycat but are not significant in the test regressions. Several commonalities also arise between the placebo and test regressions, specifically expenses, VIX, and S\&P 500 are significant and of the same sign in both regressions. Cremers and Petajisto (2009) document an inverse relation between active share (portion of a fund's portfolio different from its benchmark) and index performance and a positive relation between active share and fund expenses and turnover. Thus, these results are partially in line with the pseudo copycats in our sample being closet indexers. In summary, the results in the placebo tests are different enough from the test results to give us confidence that the results we document do not endogenously arise due to high portfolio commonality.

\section{Implications of Copycat Behavior}

Our results so far suggest that underperforming funds select targets with stronger performance, higher Morningstar Ratings, investment inflows, and greater advertising expenditures. While it may appear that this fund selection process is based on public information, does the post-copying performance of the target funds show that they are indeed run by superior managers? In other words, are the trades of targets informative of future returns even following the lag imposed by disclosure timing? If so, is the copycat successful in improving its performance? The answer to both these questions appears to be no. 
In Table 5, we report performance, flow, and fees for the target and copycat fund in the years preceding and following the initiation of copying and the resultant change in performance. We report fund performance, both relative to the average performance of all funds in the same management objective and risk-adjusted performance using the CAPM, the Fama and French (1993) three-factor model, and the Fama and French and Carhart (1997) four-factor model. As our results are highly similar across the four performance measures and across time, we focus our discussion on the fourfactor model results and the overall sample period (1991-2013, reported in Panel 1). In the year preceding the copying phase, average copycat four-factor alphas are $-3.68 \%$ per annum relative to the average target fund four=factor alpha of $0.55 \%$, a performance gap of $4.23 \%$. While average performance improves significantly for the copycat funds in the year following the initiation of copying (by approximately 3\%), the copycat fund fails to match the performance of its target, though shrinking the performance gap to $3.56 \%$. However, the overall four-factor alpha is negative and insignificant. The sub-period results reported in Panel 3 of Table 5 in the Online Appendix B are similar and consistent across sub-periods, suggesting that although the number of copycat funds varies across our sample, the average ability to realize the performance of the copied fund remains consistent. Most notably, the increase in portfolio disclosure frequency in 2004 appears to have had no impact on the performance gap between target and copycat funds. Finally, in the year following initiation of copying, though the performance of the target fund improves on average by $2.5 \%$, this increase in performance is not statistically significant.

Consistent with investors reacting to prior positive or improving performance, copycat funds realize an increase in investor allocations (an average increase of $0.95 \%$ of TNA). However, objectiveadjusted flows remain negative for the copycat fund despite the increase. Target funds likewise realize an increase in investor allocations (on average, $0.39 \%$ of TNA). This increase is net of flows that may have been captured by the copycat fund. We also observe that copycat funds typically reduce 
management expenses in the year after copying initiation (in contrast to target funds that hold constant or potentially increase management expenses).

The results in Panel 1 of Table 5 appear to suggest that copycat funds may indeed have fundpicking ability, based on the improvement in target fund alphas in the year following copycat initiation and general target performance. To examine whether this superior performance persists, we next evaluate the longer-term performance of target and copycat funds in Panel 2 of Table 5. For ease of comparison, four-factor alpha values are also presented graphically in Figure 2. Superior managers should be characterized by persistent superior performance. However, the performance of both the target and the copycat fund decays rapidly subsequent to the initiation of copying. Focusing again on the four-factor model, the performance of the target fund drops threefold in the second relative to the first year of copying ( $0.87 \%$ from $3.12 \%)$, and over the four years following initiation of copying, it drops to $0.43 \%$. Copycat performance shows a more rapid decay, widening the performance gap between the target and the copycat fund. It should be noted that these values likely overstate both copycat and target fund performance because they are impaired by survivorship bias. The worst performing copycat-target fund pairs likely drop from the sample as, on average, copying of a specific fund lasts seven quarters. We explore potential causes of the difference in short- and long-term performance of copied funds further in the paper.

\subsection{Determinants of copycat success}

We first examine what factors explain the ability of copycats to successfully mimic other fund managers. As previously discussed, accurately mimicking the target fund portfolio is constrained by infrequent holdings disclosures. Funds that trade more frequently, or which seek to hide their holdings via window dressing or portfolio pumping-type strategies will be additionally difficult to mimic. Older 
and larger funds that are likely to hold a greater range of assets in their portfolios may also be more difficult to mimic.

The copycat success determinant regression results are reported in Table 8 in the Online Appendix B. The dependent variable is the difference in gross or net returns between the copycat and target fund. Thus, in this specification, a positive coefficient value is associated with superior performance of the copycat relative to the target fund. As independent variables, we include target fund characteristics including: expense ratio, portfolio turnover ratio, log TNA, age, past performance measured by the four-factor alpha over the prior 12 months, and tracking error (all as previously defined). In addition, we augment the variable list with the number of assets in the target fund portfolio as portfolios with more assets may be more difficult to mimic successfully. The panel regressions include year fixed effects, and standard errors are clustered by portfolio. Since the results are similar between the gross and net abnormal return models and across time intervals, we focus our discussion on the net return specification for the full sample.

For the copied fund, the dominant factor influencing copycat success appears to be the expense ratio of the target fund. The higher the expense ratio, the smaller is the difference between copycat and target fund performance. Target funds with larger TNA, with less representative disclosures (higher tracking error), and who trade more frequently are more difficult to emulate, with fund size being about as influential as the expense ratio. Target fund performance is also inversely related to the past performance of target funds, suggesting that more successful funds are more difficult to copy. Finally, perhaps surprisingly, controlling for fund size, having more stocks in the target fund portfolio is predictive of greater copycat success.

A natural question that arises from this analysis is why a copycat would purposefully select a target fund that is inherently more difficult to copy (i.e., funds with high tracking errors) or is inherently more difficult to compete with on price (funds with lower expenses). One possible 
explanation is that characteristics that impede copycat success are common to superior funds. Copycats that select these funds to copy recognize the inherent challenges, but prefer an imperfect share of the performance of a superior fund to a larger proportion of the performance of an inferior fund.

This thesis also provides an alternative test for the fund-picking ability of copycat funds. The variable of interest is the change in four-factor alpha of the target fund, as this variable reflects persistence in performance, a proxy for manager skill. We partition the change in target fund performance (from Panel 2 of Table 5 in the main paper) into quartiles based on the four leading predictors of copycat success from Table 8 in the Online Appendix B (turnover, expense ratio, tracking error, and size). We report mean values for the top and bottom quartiles in Table 9 in the Online Appendix B. The objective of the analysis is to evaluate if funds that are inherently more difficult to copy are superior performers. We also test the alternative hypothesis that funds with greater target copying ability (i.e., funds with the lowest performance gap in Table 8 of Online Appendix B) also have fund-picking ability.

We find that funds with the smallest performance gaps (i.e., funds with the greatest skill in copying the target funds) appear to select funds that realize smaller drops in performance over both the two- and four-year horizons. On average, for funds in the bottom performance gap quartile (Q1), the target funds realize a statistically insignificant reduction in alpha relative to funds in the top quartile of the performance gap, which realize reductions in alpha of $4.01 \%$. Turning to the other partition variables, most of the differences in target fund performance decay are not statistically significant. There are two exceptions - high relative to low expense ratio funds appear to earn significantly worse four-factor alphas over the two-year horizon (and marginally over the four-year horizon), and high tracking error funds appear to earn significantly poorer returns than low tracking error funds over both horizons. Unfortunately, these two results have opposite implications-we hypothesized that high tracking error funds and low expense ratio funds were intrinsically more difficult to copy and hence 
would be more likely to reveal evidence of superior fund managers. Overall, these alternative tests provide, at best, very weak evidence that a subset of copycat funds can identify superior managers.

\subsection{Capturing copied fund flow}

As an alternative cut on the success of copycat behavior, we consider flow captured by the copycat fund, potentially at the cost of the target fund. Opponents to increases in required portfolio disclosures by mutual funds often argue that increased disclosure creates copycat opportunities, allowing copycats to achieve similar performance and risk exposure to the target funds while incurring minimal management costs. In practice, copycat funds can offer an identical product at a lower cost (lower expenses) due to lower management costs. If copycats can identify their superior peers ex ante, they will be able to capture a significant proportion of the flow (since retail investors are likely to be conditioning on publicly available factors such as short-term performance). In this section, we examine the factors that predict flow differences between the target and copycat funds.

We model the copycat flow effects for the target fund in two ways. First, we utilize the universe of actively managed, domestic equity funds in the CRSP database, excluding copycat and target funds, and calculate a flow-predictive model utilizing fund characteristics shown in the extant literature to influence fund flow. ${ }^{10}$ Utilizing the coefficient estimates from that model, we estimate counterfactual flow for the target fund that would have theoretically been realized in the absence of a copycat. We then relate the difference between actual and counterfactual flow for the target fund to determinant variables, focusing on factors that might render the target fund more or less attractive to investors. In the second approach, in a multivariate panel regression, we relate the difference in flow between the target and copycat funds in the year following the commencement of copying to determinant variables,

${ }^{10}$ Table 10 in the online Appendix B provides a description of the flow-predictive model. $-33-$ 
controlling for the same flow difference determinant variables. In both approaches, we cluster standard errors by fund and include year fixed effects, and we obtain similar results.

Using the first measure, the average difference between actual and counterfactual flow is -0.34 , though this average is not statistically different from zero ( $t$-test statistic 1.13). The Q1, median, and Q3 values are $-0.764,-0.19$, and -0.14 , respectively. To provide a sense of scale, based on average fund TNA values, the Q1, median, and Q3 flow differences reflect a loss of investment to copied funds of 3.3, 0.9, and 0.5 million USD per fund in the year following initiation of copying. As a proportion of average fund size (approximately 600 million USD), these values are small and significantly less than $1 \%$ of fund size.

Coefficients from the panel regression estimates using differences between actual and counterfactual flow for the target fund as the dependent variable are reported in Table 6 of the main paper. We find that exposure factors significantly influence the ability of copycats to capture flow. For example, target funds that spend more on advertising, at both the family and fund levels, earn proportionally higher flows than their counterfactual flows would indicate. Similarly, larger differences in Morningstar Ratings allow the target fund to draw proportionally greater flow. As would rationally be expected, the greater the difference in performance between the target and the copycat fund, the greater the flow to the target fund relative to its counterfactual estimate. Factors that tend to result in greater relative flow to the copycat include expense ratios and fund or family size. As asserted by opponents to increases in the required disclosure frequency for mutual funds, target funds with expenses that are relatively higher than the copycat fund attract proportionally less flow. Controlling for the discussed relations, target funds that are proportionally larger than the copycat tend to draw less proportional flow.

In the second approach, we utilize the difference in flow between the target and copycat fund as the dependent variable. The independent variable differences are calculated as the difference between 
the target and copycat fund values. Since results are consistent across time partitions, we focus our analysis on the 2004-2011 sample, as it is this period for which advertising data is available. Because the advertising data ends in 2011, we exclude copycats in 2012 and 2013 from this model. Our results (results reported in Panel 2 of Table 6 of Online Appendix B) are strikingly similar to those reported in Panel 1 of the main paper. Greater disparity between expense ratios and fund size results in greater proportional flow directed to copycat funds. Likewise, greater disparities in performance, advertising, and Morningstar Ratings result in higher relative flows to the target fund.

\section{Survival of Copycat Funds}

Our results suggest that a copycat strategy is employed primarily by distressed funds that lack a viable alternative strategy to successfully compete for investor flow. Thus, in many ways the copycat strategy reflects an act of desperation by a failing fund. However, as reported in Table 1, the average copycat copies its target for a period of time ranging from four to eight quarters. The drop in performance for the target funds occurs in later years. Therefore, an alternative hypothesis is that the copycat funds are smart enough to move on from target funds well before they stop underperforming. As a final take on the implications of copycat behavior, we examine if a copycat strategy aids in deferring mutual fund failure. In other words, we examine if smart copycats that shift strategically from superior fund to superior fund can earn significant flows and survive.

To model this effect, we utilize a semi-parametric Cox proportional hazard model, relating an indicator variable set to 1 in the month of fund failure to the flow-determinant variables described in Table 10 of the Online Appendix B. We report the results in Table 7. As these variables have previously been shown in the extant literature to influence investor flow and thus indirectly the revenue stream to mutual funds, they are effective predictors of fund viability. Consistent with prior findings, we find that lagged flow, aggregate flow, flow resulting from stale return chasing, family and fund- 
level advertising, and higher Morningstar Ratings are predictive of a higher likelihood of fund survival. Higher expenses and loads are predictive of higher failure likelihood. Controlling for the effects of all these variables, we find that copycat funds are incrementally more likely to fail relative to the universe of mutual funds, and the magnitude of the copycat indicator coefficient suggests it is one of the leading predictors of mutual fund failure. Hence, the nonsurvival of copycats implies that copying other funds is not a viable trading strategy.

\section{Conclusions}

The ability of investors to ex ante identify superior mutual fund managers capable of outperforming a risk-adjusted benchmark has been a topic of extensive debate in the finance literature. If detection of such managers is possible, the subgroup of investors most likely to possess this skill is other fund managers who have the necessary training, time, access to private information on their peers, and expertise. Our analysis of fund managers who employ copycat strategies suggests that even the most sophisticated investors (other mutual fund managers) appear unable to identify superior mutual funds or elect not to employ such strategies, perhaps out of ethical concerns. However, we note that questionable ethical behavior appears unfortunately common in the mutual fund industry. ${ }^{11}$ Thus, if a copycat strategy were viable, it would be expected to be employed by a relatively large number of funds. Our analysis suggests that relatively few actively managed mutual funds employ such strategies and those that do, do so out of desperation. Copycats select funds with strong prior performance and high investor inflows for which performance reverses shortly after copying initiation. Overall, we find little evidence that fund managers are capable of detecting other superior fund managers ex ante. Our

\footnotetext{
${ }^{11}$ For example, funds charge fees for portfolio management but then closet index (Cremers and Petajisto 2009), change fund names to reflect recent hot trends without making any changes to their portfolios (Cooper, Gulen, and Rau 2005), preferentially advertise stale performance metrics that mislead naive investors (Phillips, Pukthuanthong, and Rau forthcoming), and use fees and other characteristics to segment investors by sophistication and then provide varying levels of service to different clienteles (Houge and Wellman 2006).
} 
results on the decrease in copycatting behavior after the passage of Reg FD in 2000 are also consistent with the hypothesis that mutual funds exploit short-lived information, and the lack of outperformance by copycat funds provides evidence consistent with information models indicating that private information, but not publicly available information, can be profitable.

Our analysis is relevant to the debate on the frequency of portfolio disclosures by mutual funds. Our analysis suggests that copied funds are harmed by copycatting behavior in terms of deflected flows. However, the magnitude of the damage appears to have remained relatively constant across regulatory regimes, as has the ability of copycats to accurately replicate the target portfolio. The number of copycat funds increased following revisions to portfolio disclosure frequency, but the number of copycats in the fund population is still small, leading us to conclude that the costs to copycat behavior are likely to be small. However, we note that since our identification strategy focuses on pure copycats, we do not consider the impact of mixed or partial copycat strategies, so our results potentially understate the cost of copying. We have no reason to conclude, however, that our findings are not extendable to those settings. 


\section{References}

Admati, A., and P. Pfleiderer. 1986. A monopolistic market for information. Journal of Economic Theory 39:400-438.

. 1988. Selling and trading on information in financial markets. American Economic Review 78:96-103.

1990. Direct and indirect sale of information. Econometrica 58:901-28.

Agarwal, V., K. Mullally, Y. Tang, and B. Yang. 2012. Mandatory portfolio disclosure and stock liquidity. Working Paper, http://papers.ssrn.com/sol3/papers.cfm?abstract_id=2261522.

Bhojraj, S., Y. J. Cho, and N. Yehuda. 2012. Mutual fund family size and mutual fund performance: The role of regulatory changes. Journal of Accounting Research 50:647-84.

Biais, B., and L. Germain. 2002. Incentive compatible contracts for the sale of information. Review of Financial Studies 15:987-1003.

Brown, N. C., K. D. Wei, and R. Wermers. 2014. Analyst recommendations, mutual fund herding, and overreaction in stock prices. Management Science 60:1-20.

Carhart, M. 1997. On persistence in mutual fund performance. Journal of Finance 52:57-82.

Chalmers, J., A. Kaul, and B. Phillips. 2013. The wisdom of crowds: Mutual fund investors' aggregate asset allocation decisions. Journal of Banking and Finance 37:3318-33.

Cohen, R. B., C. Polk, and B. Silli. 2010. Best ideas. Working Paper, http://papers.ssrn.com/sol3/papers.cfm?abstract_id=1364827.

Cooper, M. J., H. Gulen, and P. R. Rau. 2005. Changing names with style: Mutual fund name changes and their effects on fund flows. Journal of Finance 60:2825-58.

Cremers, M., and A. Petajisto. 2009. How active is your fund manager? A new measure that predicts performance. Review of Financial Studies 22:3329-65.

Daniel, K., M. Grinblatt, S. Titman, and R. Wermers. 1997. Measuring mutual fund performance with characteristic-based benchmarks. Journal of Finance 52:1035-58.

Dyck, A., K. Lins, and L. Pomorski. 2013. Does active management pay? New international evidence. Review of Asset Pricing Studies 3, 200-228.

Fama, E., and K. R. French. 1993. Common risk factors in the returns on stocks and bonds. Journal of Financial Economics 33:3-56.

. 2010. Luck versus skill in the cross section of mutual fund returns. Journal of Finance 65:1915-47. 
Ferson, W., and M. Kim. 2012. The factor structure of mutual fund flows. International Journal of Portfolio Analysis and Management 1:112-43.

Ferson, W., and V. Warther. 1996. Evaluating fund performance in a dynamic market. Financial Analyst Journal 52:20-28.

Frank, M., J. Poterba, D. Shackelford, and J. Shoven. 2004. Copycat funds: Information disclosure regulations and the returns to active management in the mutual fund industry. Journal of Law and Economics 47:515-41.

Frazzini, A., and O. A. Lamont. 2008. Dumb money: Mutual fund flows and the cross-section of stock returns. Journal of Financial Economics 88:299-322.

Gallaher, S., R. Kaniel, and L. T. Starks. 2008. Advertising and mutual funds: From families to individual funds. Working Paper, http://papers.ssrn.com/sol3/papers.cfm?abstract_id=1362535.

Garcia, D., and J. Vanden. 2009. Information acquisition and mutual funds. Journal of Economic Theory 144:1965-95.

Gruber, M. 1996. Another puzzle: The growth in actively managed mutual funds. Journal of Finance 51:783-810.

Houge, T., and J. Wellman. 2006. The use and abuse of mutual fund expenses. Journal of Business Ethics 70:23-32.

Jensen, M. C. 1968. The performance of mutual funds in the period 1945-1964. Journal of Finance 23:389-416.

Lakonishok, J., A. Shleifer, and R. Vishny. 1992. The impact of institutional trading on stock prices. Journal of Financial Economics 32:23-43.

Lou, D. 2012. A flow-based explanation for return predictability. Review of Financial Studies 25, 3457-89.

Mamaysky, H., M. Spiegel, and H. Zhang. 2008. Estimating the dynamics of mutual fund alphas and betas. Review of Financial Studies 21:233-64.

Nanda, V., J. Wang, and L. Zheng. 2009. The ABCs of mutual funds: On the introduction of multiple share classes. Journal of Financial Intermediation 18:329-361.

Parida, S., and T. Teo. 2011. The impact of more frequent portfolio disclosure on mutual fund performance. Working Paper, http://papers.ssrn.com/sol3/papers.cfm?abstract_id=2097883.

Petajisto, A. 2013. Active share and mutual fund performance. Financial Analysts Journal 69, 73-93.

Phillips, B., K. Pukthuanthong, and P. R. Rau. Forthcoming. Past performance may be an illusion: Performance, flows, and fees in mutual funds, Critical Finance Review. 
Pomorski, L. 2009. Follow the leader: Peer effects in mutual fund portfolio decisions. Working Paper, http://papers.ssrn.com/sol3/papers.cfm?abstract_id=954116.

Reuter, J., and E. Zitzewitz. 2006. Do ads influence editors? Advertising and bias in the financial media. Quarterly Journal of Economics 121:197-227.

Sapp, T., and A. Tiwari. 2004. Does stock return momentum explain the "smart money" effect? Journal of Finance 59:2605-22.

Shive, S., and H. Yun. 2013. Are mutual funds sitting ducks? Journal of Financial Economics 107:220-37.

Sias, R. 2004. Institutional herding. Review of Financial Studies 17:165-206.

Verbeek, M., and Y. Wang. 2013. Better than the original? The relative success of copycat funds. Journal of Banking and Finance 37:3454-71.

Wermers, R. 1999. Mutual fund herding and the impact on stock prices. Journal of Finance 54:581622.

2000. Mutual fund performance: An empirical decomposition into stock-picking talent, style, transaction costs, and expenses. Journal of Finance 55:1655-95.

2004. Is money really "smart"? New evidence on the relation between mutual fund flows, manager behavior and performance persistence. Working Paper, http://papers.ssrn.com/sol3/papers.cfm?abstract_id=414420.

Zheng, L., 1999. Is money smart? A study of mutual fund investor's fund selection ability. Journal of Finance 54:901-33. 
Table 1

Incidence of copycat funds

\begin{tabular}{|c|c|c|c|c|c|c|c|c|c|c|c|c|}
\hline \multirow[t]{2}{*}{ Min $\% \Delta$ weights in common } & \multicolumn{3}{|c|}{75} & \multicolumn{3}{|c|}{80} & \multicolumn{3}{|l|}{85} & \multicolumn{3}{|c|}{90} \\
\hline & $N$ & Mean & Std. & $N$ & Mean & Std. & $N$ & Mean & Std. & $N$ & Mean & Std. \\
\hline
\end{tabular}

1991-1999

\begin{tabular}{|c|c|c|c|c|c|c|c|c|c|}
\hline Unique copycat funds & 493 & & & & & 278 & & 222 & \\
\hline Unique target funds & 292 & & & & & 224 & & 125 & \\
\hline Quarters copying & & 7.21 & 5.43 & 8.92 & 4.96 & 7.88 & 4.94 & 6.14 & 2.62 \\
\hline$\%$ Weights in common & & 83.09 & 5.03 & 85.73 & 6.35 & 90.43 & 5.29 & 96.35 & 4.82 \\
\hline$\% \Delta$ Weights in common & & 78.21 & 10.81 & 84.81 & 10.79 & 91.21 & 14.09 & 95.72 & 10.50 \\
\hline
\end{tabular}

2000-2003

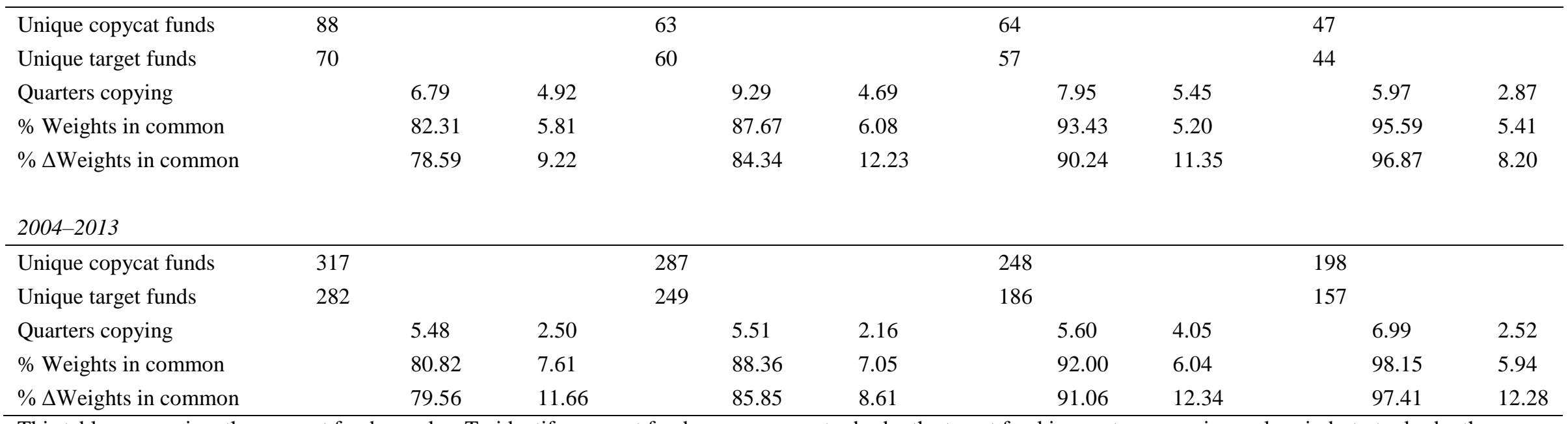

This table summarises the copycat fund samples. To identify copycat funds, we compare trades by the target fund in quarter or semiannual period $t$ to trades by the copycat fund in period $t+1$, and form four samples utilizing varying matching criteria. In the first sample, the change in portfolio weights is required to match by at least $75 \%$ in adjacent periods for at least two quarters. In the subsequent samples, the minimum matching criteria is increased from $80 \%$ to $90 \%$. $\%$ weights in common is the percentage of portfolio weights in common between the target and copycat fund in period $t$ and $t+1$, respectively. The sample is partitioned into three time periods, the period pre-dating establishment of Fair Disclosure Regulations (Reg FD, 1991-1999), the period after Reg FD and preceding the requirement for quarterly holdings disclosures by mutual funds (2000-2003), and the period after both Reg FD and quarterly holdings disclosure requirements (2004-2013). 
Table 2

Copycat fund validation tests

\begin{tabular}{|c|c|c|c|c|c|c|c|c|c|}
\hline Panel 1 & & & & ycat Por & lio OLS & & & & \\
\hline Model & 1 & 2 & 3 & 4 & 5 & 6 & 7 & 8 & 9 \\
\hline$\Delta$ Weight target fund ${ }_{\mathrm{i}, t-1}$ & $0.35^{* * *}$ & $0.19^{* * *}$ & $0.20^{* * *}$ & $0.37^{* * *}$ & $0.28^{* * * *}$ & $0.55^{* * *}$ & $0.55^{* * *}$ & $0.49^{* * *}$ & $0.46^{* * *}$ \\
\hline & $(4.01)$ & (2.99) & $(2.83)$ & $(4.17)$ & $(3.33)$ & $(6.32)$ & $(6.31)$ & $(5.98)$ & $(5.35)$ \\
\hline Weight copycat fund $\mathrm{i}_{\mathrm{i}, t-1}$ & & & & & & $-0.63^{* * *}$ & $-0.58^{* * *}$ & $-0.54^{* * * *}$ & $-0.55^{* * * *}$ \\
\hline & & & & & & $(-7.58)$ & $(-6.45)$ & $(-6.07)$ & $(-6.17)$ \\
\hline Herding $_{\mathrm{i}, t-1}$ & & & & & $0.18^{* * * *}$ & & & & $0.10^{*}$ \\
\hline & & & & & $(2.70)$ & & & & $(1.77)$ \\
\hline Stock return $_{\mathrm{i}, t}$ & & $0.18^{* * *}$ & $0.15^{* *}$ & $0.17^{* *}$ & $0.19^{* * * *}$ & & $0.08^{*}$ & $0.13^{* * *}$ & $0.09^{*}$ \\
\hline & & $(3.05)$ & $(2.16)$ & $(2.44)$ & $(2.73)$ & & $(1.85)$ & $(2.63)$ & $(1.70)$ \\
\hline Stock return $_{\mathrm{i}, t-1}$ & & $0.39^{* * *}$ & & $0.49^{* * * *}$ & $0.35^{* * * *}$ & & & $0.67^{* * * *}$ & $0.65^{* * *}$ \\
\hline & & $(4.68)$ & & $(5.70)$ & $(4.09)$ & & & $(7.97)$ & $(7.63)$ \\
\hline Stock return $_{\mathrm{i}, t-5}$ to $t-1$ & & & $0.38^{* * *}$ & & & & $0.88^{* * *}$ & & \\
\hline & & & $(4.32)$ & & & & $(9.52)$ & & \\
\hline Stock turnover $_{i, t}$ & & & & 0.00 & 0.00 & & & & \\
\hline & & & & $(0.05)$ & $(0.04)$ & & & & \\
\hline Stock turnover $r_{i, t-1}$ & & & & -0.02 & -0.02 & & & & \\
\hline & & & & $(-0.38)$ & $(-0.56)$ & & & & \\
\hline Adjusted $R^{2}$ & 0.01 & 0.01 & 0.01 & 0.01 & 0.02 & 0.03 & 0.06 & 0.04 & 0.06 \\
\hline$N$ & 3,547 & 3,474 & 3,118 & 3,383 & 3,359 & 3,228 & 2,919 & 3,174 & 3,093 \\
\hline
\end{tabular}

This panel reports regression estimates relating the change in portfolio holding weight of stock $i$ for the copycat fund to the change in weight in stock $i$ for the target fund plus controls for information flows and herding at the initiation of the copying phase. The return to stock $i$ in periods $t, t-1$, and over the prior year (quarters $t-5$ to $t-1$ ) and turnover of the shares for stock $i$ in period $t$ and $t-1$ are used as proxies for information flows. Herding measures institutional investor herding for stock $i$ in period $t$, calculated as in Sias (2004), which measures the degree to which investors follow the trades of other investors in consecutive periods. Standardized regression coefficients are reported with $t$-statistics in parenthesis. $T$-statistics are calculated with standard errors clustered by portfolio with the Newey-West correction for potential autocorrelation and heteroscedasticity. Each model includes year/quarter or year/six-month period fixed effects depending on data availability. Results are reported for the aggregate sample 1991-2013. $N$ is the average number of stocks across sectional regressions. Significance at the $10 \%, 5 \%$, and $1 \%$ levels is indicated by ${ }^{* * *}$, and ${ }^{* * *}$, respectively. 
Table 2

Continued

\section{Panel 2}

Target Portfolio OLS Model

\begin{tabular}{|c|c|c|c|c|c|}
\hline Model & 1 & 2 & 3 & 4 & 5 \\
\hline \multirow[t]{2}{*}{$\Delta$ Weight copycat fund $_{\mathrm{i}, t-1}$} & 0.01 & 0.01 & 0.01 & 0.03 & -0.01 \\
\hline & $(0.78)$ & $(0.26)$ & $(0.09)$ & $(0.45)$ & $(0.21)$ \\
\hline \multirow[t]{2}{*}{ Weight target fund ${ }_{\mathrm{i}, t-1}$} & & & $-0.26^{* * *}$ & $-0.44^{* * *}$ & $-0.45^{* * *}$ \\
\hline & & & $(-3.46)$ & $(-5.27)$ & $(-5.48)$ \\
\hline \multirow[t]{2}{*}{ Stock return $_{\mathrm{i}, t}$} & & $0.27^{* * *}$ & & $0.38^{* * *}$ & $0.23^{* * *}$ \\
\hline & & $(3.52)$ & & $(4.54)$ & $(2.93)$ \\
\hline \multirow[t]{2}{*}{ Stock return $_{\mathrm{i}, t-1}$} & & $0.16^{* * * *}$ & & $0.15^{* * *}$ & \\
\hline & & $(2.95)$ & & $(2.79)$ & \\
\hline \multirow[t]{2}{*}{ Stock return $_{\mathrm{i}, t-5 \text { to } t-1}$} & & & & & $0.40^{* * *}$ \\
\hline & & & & & $(5.16)$ \\
\hline \multirow[t]{2}{*}{ Stock turnover $_{\mathrm{i}, t}$} & -0.01 & 0.00 & -0.06 & -0.08 & 0.00 \\
\hline & $(-0.27)$ & $(0.04)$ & $(-1.27)$ & $(1.51)$ & $(0.09)$ \\
\hline \multirow[t]{2}{*}{ Stock turnover $_{\mathrm{i}, t-1}$} & 0.00 & -0.02 & 0.00 & 0.00 & -0.02 \\
\hline & $(0.02)$ & $(-0.31)$ & $(0.02)$ & $(0.02)$ & $(-0.22)$ \\
\hline Adjusted $R^{2}$ & 0.001 & 0.004 & 0.005 & 0.011 & 0.007 \\
\hline$N$ & 6,448 & 6,107 & 5,827 & 5,642 & 5,354 \\
\hline
\end{tabular}

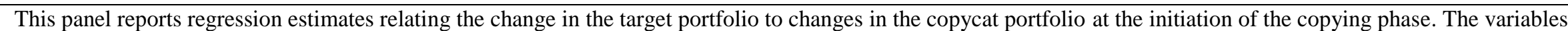
are as described in Panel 1. Standardized regression coefficients are reported with $t$-statistics in parentheses. $T$-statistics are calculated with standard errors clustered by portfolio with the Newey-West correction for potential autocorrelation and heteroscedasticity. Each model includes year/quarter or year/six-month period fixed effects depending on data availability. Results are reported for the aggregate sample 1991-2013. $N$ is the average number of stocks across sectional regressions. Significance at the $10 \%, 5 \%$, and $1 \%$ levels is indicated by ${ }^{*},{ }^{* *}$, and ${ }^{* * *}$, respectively. 
Table 3

Comparative characteristics of target and copycat funds: Objective-adjusted fund characteristics

\begin{tabular}{|c|c|c|c|c|c|c|c|c|}
\hline \multirow[b]{2}{*}{ Variable } & \multicolumn{4}{|c|}{ 1991-1999 } & \multicolumn{4}{|c|}{$2000-2003$} \\
\hline & Copycat & Target & Diff. & $p$-value & Copycat & Target & Diff. & $p$-value \\
\hline Size $_{m-1}$ & -85.40 & 129.91 & $215.31^{* *}$ & 0.054 & -134.07 & 159.96 & $294.03^{* * * *}$ & 0.008 \\
\hline Family size $_{m-1}$ & -175.92 & 270.05 & $445.96^{* *}$ & 0.040 & -172.66 & 345.50 & $518.16^{* *}$ & 0.019 \\
\hline Flow $_{6 m-1}$ & -0.56 & 0.53 & $1.09^{* * *}$ & 0.005 & -0.61 & 0.42 & $1.03^{* * *}$ & 0.005 \\
\hline Flow std. $y-1$ & 1.01 & -1.08 & $-2.09^{* *}$ & 0.037 & 1.58 & -1.50 & $-3.08^{* *}$ & 0.022 \\
\hline Family flow $6 m-1$ & 0.06 & 0.46 & 0.40 & 0.179 & 0.05 & 0.58 & $0.53^{*}$ & 0.089 \\
\hline Return $_{6 m-1}$ & -3.06 & 1.19 & $4.26^{* * *}$ & 0.004 & -4.16 & 1.16 & $5.32^{* * *}$ & 0.002 \\
\hline Return std. $y-1$ & 1.37 & -0.03 & $-1.40^{* *}$ & 0.043 & 1.91 & -0.05 & $-1.96^{* *}$ & 0.022 \\
\hline$\Delta$ Return $_{y-1}$ & -4.18 & 3.27 & $7.45^{* *}$ & 0.015 & -5.36 & 4.48 & $9.84^{* * *}$ & 0.003 \\
\hline CAPM $\alpha_{2 y-1}$ & -1.20 & 1.85 & $3.04^{* * *}$ & 0.006 & -1.38 & 1.60 & $2.98^{* * * *}$ & 0.006 \\
\hline Three-factor $\alpha_{2 y-1}$ & -1.33 & 1.53 & $2.86^{* * *}$ & 0.006 & -1.13 & 1.67 & $2.80^{* * *}$ & 0.007 \\
\hline Four-factor $\alpha_{2 y-1}$ & -1.36 & 0.80 & $2.15^{* * *}$ & 0.012 & -2.12 & 0.71 & $2.84^{* * *}$ & 0.007 \\
\hline Total load $_{q-1}$ & -0.79 & 0.18 & $0.97^{*}$ & 0.096 & -0.64 & 0.17 & $0.81^{*}$ & 0.089 \\
\hline Expense ratio $q-1$ & -0.34 & -0.02 & $0.33^{* *}$ & 0.017 & -0.33 & -0.02 & $0.31^{* *}$ & 0.019 \\
\hline $12 \mathrm{~b}-1_{q-1}$ & -0.08 & 0.05 & 0.13 & 0.131 & -0.09 & 0.05 & 0.13 & 0.108 \\
\hline Turnover $_{y-1}$ & 23.48 & -23.54 & $-47.01^{* *}$ & 0.032 & 32.65 & -31.86 & $-64.51^{* * *}$ & $<0.001$ \\
\hline Tracking error $_{q-1}$ & 0.57 & -0.24 & $-0.81^{* * *}$ & 0.008 & 0.62 & -0.24 & $-0.87^{* * *}$ & 0.009 \\
\hline$N$ & 493 & 292 & & & 88 & 70 & & \\
\hline
\end{tabular}




\begin{tabular}{|c|c|c|c|c|}
\hline \multirow[b]{2}{*}{ Variable } & \multicolumn{4}{|c|}{ 2004-2011 } \\
\hline & Copycat & Target & Diff. & p-value \\
\hline Size $_{m-1}$ & -123.49 & 175.45 & $298.94^{*}$ & 0.010 \\
\hline Family size $_{m-1}$ & -133.34 & 389.43 & $522.77^{* *}$ & 0.025 \\
\hline Flow $_{6 m-1}$ & -0.50 & 0.51 & $1.00^{* * *}$ & 0.007 \\
\hline Flow std. $y-1$ & 1.29 & -1.20 & $-2.48^{* *}$ & 0.031 \\
\hline Family flow $_{6 m-1}$ & 0.07 & 0.45 & 0.38 & 0.154 \\
\hline Return $_{6 m-1}$ & -3.09 & 0.89 & $3.98^{* * * *}$ & 0.003 \\
\hline Return std. $y-1$ & 1.95 & -0.04 & $-1.99^{* *}$ & 0.026 \\
\hline$\Delta$ Return $_{y-1}$ & -5.32 & 4.25 & $9.57^{* * * *}$ & 0.004 \\
\hline CAPM $\alpha_{2 y-1}$ & -1.11 & 2.14 & $3.24^{* * * *}$ & 0.007 \\
\hline Three-factor $\alpha_{2 y-1}$ & -1.41 & 2.21 & $3.62^{* * * *}$ & 0.005 \\
\hline Four-factor $\alpha_{2 y-1}$ & -1.99 & 0.59 & $2.57^{* * * *}$ & 0.009 \\
\hline Total load $_{q-1}$ & -0.76 & 0.20 & $0.96^{*}$ & 0.078 \\
\hline Expense ratio $_{q-1}$ & -0.32 & -0.02 & $0.30^{* *}$ & 0.023 \\
\hline $12 \mathrm{~b}-1_{q-1}$ & -0.10 & 0.04 & $0.14^{*}$ & 0.092 \\
\hline Ad spending $_{q-1}$ & -702.29 & -520.76 & 181.53 & 0.281 \\
\hline Turnover $y-1$ & 27.42 & -25.48 & $-52.9^{* * *}$ & 0.001 \\
\hline Ad spending HPR ${ }_{q-1}$ & -51.61 & 147.23 & $198.84^{* * *}$ & 0.002 \\
\hline Ad spending no HPR ${ }_{q-1}$ & -32.31 & 63.75 & $96.07^{* * *}$ & 0.005 \\
\hline Tracking error $_{q-1}$ & 0.43 & -0.28 & $-0.71^{* *}$ & 0.018 \\
\hline$N$ & 317 & 282 & & \\
\hline
\end{tabular}

This panel reports summary statistics for the target and copycat funds in the period of copying initiation. In the variable notation $m, q$, and $y$ represent month, quarter,

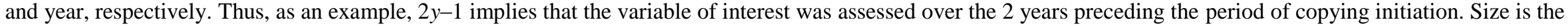
total net assets (TNA) managed by the fund or fund family excluding the fund of interest, reported in millions USD. Flow is measured as: (TNA $A_{i, t}-T N A_{i, t}$ ${ }_{1} \times\left(1+\right.$ Return $\left.\left._{i, t}\right)\right) / T N A_{i, t-1}$ in month $t$ for fund $i$. Performance is measured as the gross return net of expenses over the prior six months in addition to risk-adjusted performance based on the CAPM, the Fama and French three-factor and four-factor model, using the Fama and French (1993) and Carhart (1997) factors. Expenses are total annual management expenses charged by the fund scaled by year-end TNA. 12b-1 is the $12 \mathrm{~b}-1$ expense charged by the fund scaled by year-end TNA. Total load is the total front, deferred, and rear-end load fees charged by the fund as a percentage of investment. Advertising spending is total advertising spending by the fund family

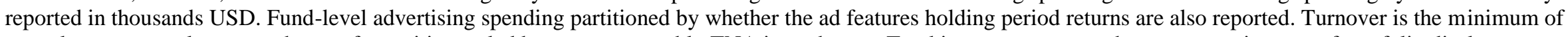
annual aggregate sales or purchases of securities scaled by average monthly TNA in each year. Tracking error captures the representativeness of portfolio disclosures and is measured as the standard deviation of the return gap between realized fund returns and style benchmark returns over the prior five months. Mean values of each

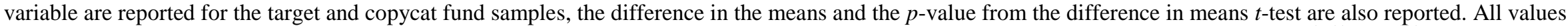
are in excess of the average value to all funds in the same management objective. Significance at the $10 \%, 5 \%$, and $1 \%$ levels is indicated by ${ }^{*}{ }^{* *}$, and ${ }^{* * *}$, respectively. 
Table 4

Multivariate determinants of fund mimicking:

Objective-adjusted values, full sample, 1991-2013

\begin{tabular}{|c|c|c|c|c|c|c|c|c|}
\hline \multirow{3}{*}{$\begin{array}{l}\text { Model } \\
\text { Variable }\end{array}$} & \multicolumn{4}{|l|}{1} & \multicolumn{4}{|l|}{2} \\
\hline & \multicolumn{2}{|l|}{ Copycat } & \multicolumn{2}{|l|}{ Target } & \multicolumn{2}{|l|}{ Copycat } & \multicolumn{2}{|l|}{ Target } \\
\hline & Coef. & $t$-stat & Coef. & $t$-stat & Coef. & $t$-stat & Coef. & $t$-stat \\
\hline Size $_{m-1}$ & $-0.16^{* *}$ & -2.25 & $0.14^{* *}$ & 2.35 & $-0.14^{* *}$ & -2.39 & $0.15^{* * *}$ & 3.02 \\
\hline Family size $_{m-1}$ & $-0.21^{* * *}$ & -3.07 & $0.12^{* *}$ & 2.16 & $-0.17^{* * *}$ & -3.00 & $0.08^{*}$ & 1.79 \\
\hline Flow $_{6 m-1}$ & $-0.10^{* * *}$ & -2.16 & $0.27^{* * *}$ & 3.33 & $-0.10^{*}$ & -1.82 & $0.19^{* * *}$ & 2.59 \\
\hline Flow std. $y-1$ & $0.10^{*}$ & 1.68 & 0.03 & 0.32 & $0.15^{* *}$ & 2.21 & 0.01 & 0.39 \\
\hline Family flow ${ }_{6 m-1}$ & -0.02 & -0.27 & $0.11^{* *}$ & 2.27 & -0.06 & -1.28 & $0.13^{* *}$ & 2.28 \\
\hline Return $_{6 m-1}$ & -0.04 & -1.38 & 0.04 & 1.47 & -0.04 & -0.71 & 0.04 & 1.03 \\
\hline Return std. $y-1$ & $0.12^{* *}$ & 2.34 & 0.05 & 1.55 & $0.20^{* * *}$ & 2.94 & 0.04 & 1.36 \\
\hline Objective-adj. return $_{2 y-1}$ & $-0.12^{*}$ & -1.89 & $0.14^{* *}$ & 2.10 & & & & \\
\hline Four-factor $\alpha_{2 y-1}$ & & & & & $-0.13^{* *}$ & -2.32 & $-0.15^{* *}$ & -2.49 \\
\hline Total load $_{m-1}$ & 0.02 & 0.84 & 0.01 & 0.27 & 0.02 & 0.85 & 0.01 & 0.63 \\
\hline Expense ratio $_{q-1}$ & $0.13^{* *}$ & 2.38 & 0.02 & 1.03 & $0.09^{* *}$ & 2.05 & 0.02 & 1.17 \\
\hline $12 \mathrm{~b}-1_{a-1}$ & 0.07 & 1.24 & 0.04 & 1.30 & 0.07 & 1.50 & 0.05 & 1.31 \\
\hline Turnover $_{v-1}$ & 0.05 & 1.33 & 0.03 & 0.37 & $0.10^{* *}$ & 2.04 & 0.02 & 0.54 \\
\hline Tracking error $_{q-1}$ & $0.24^{* * *}$ & 3.70 & $-0.10^{* *}$ & -2.25 & $0.15^{* *}$ & 2.47 & $-0.10^{* *}$ & -2.18 \\
\hline 2000-2003 indicator & $-0.24^{* * *}$ & -3.66 & & & $-0.24^{* * *}$ & -3.21 & & \\
\hline $2004-2010$ indicator & $-0.10^{*}$ & -1.98 & & & $-0.20^{* * *}$ & -2.96 & & \\
\hline \multicolumn{9}{|l|}{ State variables: } \\
\hline Aggregate flow ${ }_{q-1}$ & $0.12^{* * * *}$ & 2.37 & $0.13^{* *}$ & 2.49 & $0.08^{*}$ & 1.94 & $0.13^{* *}$ & 2.10 \\
\hline $\mathrm{S} \& \mathrm{P} 500_{q-1}$ & -0.02 & -1.09 & -0.05 & -1.23 & -0.07 & -1.58 & $-0.09^{*}$ & -1.80 \\
\hline VIX $_{q-1}$ & $0.37^{* * *}$ & 4.39 & $0.12^{* *}$ & 2.28 & $0.27^{* * *}$ & 3.90 & $0.14^{* * *}$ & 2.85 \\
\hline McFadden $R^{2}$ & 0.17 & & 0.13 & & 0.20 & & 0.16 & \\
\hline$N$ & 5,880 & & 4,261 & & 5,880 & & 4,261 & \\
\hline
\end{tabular}

This panel reports multivariate logit models which examine the determinants of copycat behavior. The dependent variable is an indicator variable set to 1 in the period which copying commences. Copycat and target fund characteristics are examined in separate models. The independent variables are as described in Table 3, with the exception of the market state variables which are aggregate flow to all actively managed equity funds, the return to the S\&P 500 index and the mean daily VIX index all measured over the period prior to copying initiation. Standardized coefficient values are reported, with associated $t$ statistics calculated with standard errors clustered by fund. Each model includes year/quarter or year-six-month period fixed effects (as appropriate). Significance at the $10 \%, 5 \%$, and $1 \%$ levels is indicated by ${ }^{*},{ }^{* *}$, and ${ }^{* * *}$, respectively. 
Table 5

Performance implications of copycat behavior

Panel 1 Full Sample

\begin{tabular}{|c|c|c|c|c|c|c|c|c|}
\hline & \multicolumn{4}{|l|}{ Copycat } & \multicolumn{4}{|l|}{ Target } \\
\hline & Pre & Post & Diff & $t$-stat & Pre & Post & Diff & $t$-stat \\
\hline \multicolumn{9}{|c|}{ Full Sample 1991-2013 } \\
\hline Objective-adj. return & $\begin{array}{l}-0.14^{* * *} \\
(-2.49)\end{array}$ & $\begin{array}{l}-0.03 \\
(-1.27)\end{array}$ & $0.11^{*}$ & 1.80 & $\begin{array}{c}0.37^{\text {**** }} \\
(3.87)\end{array}$ & $\begin{array}{c}0.67^{* * * *} \\
(5.35)\end{array}$ & $0.30^{* * * * *}$ & 4.29 \\
\hline CAPM $\alpha$ & $\begin{array}{l}-2.40^{\text {**** }} \\
(-2.60)\end{array}$ & $\begin{array}{l}-1.29^{*} \\
(-1.75)\end{array}$ & 1.11 & 1.32 & $\begin{array}{l}1.08 \\
(1.29)\end{array}$ & $\begin{array}{c}5.05^{* * *} \\
(4.43)\end{array}$ & $3.97^{* *}$ & 3.18 \\
\hline Three-factor $\alpha$ & $\begin{array}{l}-2.56^{* * *} \\
(-3.60)\end{array}$ & $\begin{array}{l}-0.78 \\
(-1.11)\end{array}$ & 1.78 & 1.59 & $\begin{array}{c}2.80^{*} \\
(1.69)\end{array}$ & $\begin{array}{c}5.44^{* * *} \\
(3.67)\end{array}$ & $2.64^{* * *}$ & 2.18 \\
\hline Four-factor $\alpha$ & $\begin{array}{l}-3.68^{* * * *} \\
(-3.38)\end{array}$ & $\begin{array}{l}-0.44 \\
(-0.28)\end{array}$ & $3.24^{* * *}$ & 2.22 & $\begin{array}{l}0.55 \\
(0.34)\end{array}$ & $\begin{array}{l}3.12^{*} \\
(1.91)\end{array}$ & $2.57^{* *}$ & 2.03 \\
\hline Objective-adj. flow & $\begin{array}{l}-1.37^{\text {*** }} \\
(-2.84)\end{array}$ & $\begin{array}{l}-0.42 \\
(-0.56)\end{array}$ & $0.95^{* *}$ & 2.52 & $\begin{array}{l}0.78^{* *} \\
(2.05)\end{array}$ & $\begin{array}{c}1.17^{* * *} \\
(2.86)\end{array}$ & $0.39^{* *}$ & 2.10 \\
\hline Expense ratio & $\begin{array}{l}1.43^{* * * *} \\
(3.31)\end{array}$ & $\begin{array}{c}0.88^{\text {*** }} \\
(3.33)\end{array}$ & $-0.55^{* *}$ & -2.40 & $\begin{array}{c}1.18^{* *} \\
(2.05)\end{array}$ & $\begin{array}{l}1.27^{* *} \\
(2.25)\end{array}$ & 0.10 & 1.29 \\
\hline$N$ & 898 & 898 & & & 644 & 644 & & \\
\hline
\end{tabular}

This panel reports performance, flow, and expenses for the copycat and target fund in the year preceding (Pre) and following (Post) the period in which the copying phase commences. Objective-adjusted return is net fund return in excess of the average net return to all funds in the management objective of the fund. Risk-adjusted returns are calculated using the CAPM, Fama and French (1993) three-factor model and a four-factor model using the Fama and French (1993) and Carhart (1997) factors. Flow is measured as: $\left(T N A_{i, t}-T N A_{i, t-1} \times\left(1+\right.\right.$ Return $\left.\left._{i, t}\right)\right) / T N A_{i, t-1}$ in year $t$ for fund $i$ in excess of the average flow to all funds in the management objective of fund $i$. Expense are the total annual management expenses charged by the fund scaled by year-end TNA. Mean values of each variable are reported for the target and copycat fund samples, the difference in the means and the test statistic from difference in means $t$-test are also reported. Significance at the $10 \%, 5 \%$, and $1 \%$ levels is indicated by ${ }^{*}, * *$, and ${ }^{* * *}$, respectively. 
Table 5

\section{Continued}

Panel 2 Average copycat and target fund performance by year (full sample, 1991-2013)

\begin{tabular}{|c|c|c|c|c|c|}
\hline \multirow[b]{2}{*}{ Year of copying } & \multicolumn{5}{|l|}{ Copycat } \\
\hline & 1 & 2 & 3 & 4 & $4-1$ \\
\hline Obj-adj. return & $\begin{array}{l}-0.03 \\
(-1.27)\end{array}$ & $\begin{array}{l}-0.04 \\
(-1.53)\end{array}$ & $\begin{array}{l}-0.08^{* *} \\
(-2.19)\end{array}$ & $\begin{array}{c}-0.11^{* * *} \\
(-2.87)\end{array}$ & $\begin{array}{l}-0.08^{*} \\
(-1.67)\end{array}$ \\
\hline CAPM $\alpha$ & $\begin{array}{l}-1.29 \\
(-1.75)\end{array}$ & $\begin{array}{l}-1.09 \\
(-1.52)\end{array}$ & $\begin{array}{l}-1.89^{* *} \\
(-2.14)\end{array}$ & $\begin{array}{l}-1.48^{*} \\
(-1.78)\end{array}$ & $\begin{array}{l}-0.19 \\
(-1.48)\end{array}$ \\
\hline Three-factor $\alpha$ & $\begin{array}{l}-0.78 \\
(-1.11)\end{array}$ & $\begin{array}{l}-1.88^{\text {** }} \\
(-2.06)\end{array}$ & $\begin{array}{l}-2.33^{* * *} \\
(-2.79)\end{array}$ & $\begin{array}{l}-2.59^{* * *} \\
-3.14)\end{array}$ & $\begin{array}{l}-1.82^{*} \\
(-1.95)\end{array}$ \\
\hline Four-factor $\alpha$ & $\begin{array}{l}-0.44 \\
(-0.28)\end{array}$ & $\begin{array}{l}-1.79^{\text {** }} \\
(-2.23)\end{array}$ & $\begin{array}{l}-2.40^{* * *} \\
(-2.70)\end{array}$ & $\begin{array}{l}-3.68^{\text {*** }} \\
(-3.23)\end{array}$ & $\begin{array}{l}-3.24^{* *} \\
(-2.49)\end{array}$ \\
\hline$N$ & 898 & 898 & 898 & 898 & 898 \\
\hline
\end{tabular}

\begin{tabular}{|c|c|c|c|c|c|}
\hline \multirow[b]{2}{*}{ Year of copying } & \multicolumn{5}{|l|}{ Target } \\
\hline & 1 & 2 & 3 & 4 & $4-1$ \\
\hline \multirow[t]{2}{*}{ Obj-adj. return } & $0.67^{* * *}$ & $0.78^{* * *}$ & $0.53^{* * *}$ & $0.48^{* * *}$ & $-0.19^{* * *}$ \\
\hline & $(5.35)$ & $(5.78)$ & $(4.12)$ & $(4.08)$ & $(-3.36)$ \\
\hline \multirow[t]{2}{*}{ CAPM $\alpha$} & $5.05^{* * * *}$ & $2.76^{* * * *}$ & 0.99 & $1.54^{*}$ & $-3.51^{* * *}$ \\
\hline & $(4.43)$ & $(2.36)$ & $(1.42)$ & $(1.76)$ & $(-3.20)$ \\
\hline \multirow[t]{2}{*}{ Three-factor $\alpha$} & $5.44^{* * * *}$ & $3.15^{* * *}$ & $1.76^{*}$ & $2.56^{* * *}$ & $-2.88^{* *}$ \\
\hline & $(3.67)$ & $(3.12)$ & $(1.77)$ & $(2.73)$ & $(-2.33)$ \\
\hline \multirow[t]{2}{*}{ Four-factor $\alpha$} & $3.12^{*}$ & 0.87 & 1.57 & 0.43 & $-2.69^{*}$ \\
\hline & $(1.91)$ & $(0.47)$ & $(0.80)$ & $(0.38)$ & $(-1.67)$ \\
\hline$N$ & 644 & 644 & 644 & 644 & 644 \\
\hline
\end{tabular}

This panel reports annual performance, flow, and expenses for the copycat and target fund following the quarter in which the copying phase commences. The variables are as defined in Panel 1 of Table 5. Mean values of each variable are reported for the target and copycat fund samples, the difference in the means and the test statistic from difference in means $t$-test are also reported. Significance at the $10 \%, 5 \%$, and $1 \%$ levels is indicated by ${ }^{*}, * *$, and ${ }^{* * *}$, respectively. 
Table 6

Captured flow

Dependent Variable Difference between actual and counterfactual flow for the target fund

\begin{tabular}{|c|c|c|c|c|}
\hline & $\begin{array}{l}\text { Full } \\
\text { Sample }\end{array}$ & 1991-1999 & $2000-2003$ & 2004-2011 \\
\hline$\Delta$ Expense ratio & $\begin{array}{c}-0.30^{\text {**:*3: }} \\
(-4.13)\end{array}$ & $\begin{array}{l}-0.48^{* * *} \\
(-6.27)\end{array}$ & $\begin{array}{c}-0.38^{\text {***** }} \\
(-3.37)\end{array}$ & $\begin{array}{l}-0.28^{* * * *} \\
(-3.74)\end{array}$ \\
\hline$\Delta$ Family level advertising & & & & $\begin{array}{l}0.09^{*} \\
(1.82)\end{array}$ \\
\hline$\Delta$ Fund level advertising & & & & $\begin{array}{c}0.47^{* * *} \\
(5.55)\end{array}$ \\
\hline$\Delta$ Objective-adjusted return & $\begin{array}{c}0.34^{* * *} \\
(4.57)\end{array}$ & $\begin{array}{c}0.38^{* * * *} \\
(3.86)\end{array}$ & $\begin{array}{c}0.48^{* * * *} \\
(5.42)\end{array}$ & $\begin{array}{c}0.44^{* * * *} \\
(5.57)\end{array}$ \\
\hline$\Delta$ Fund TNA & $\begin{array}{l}-0.12^{* *} \\
(-2.57)\end{array}$ & $\begin{array}{l}-0.09^{*} \\
(-1.77)\end{array}$ & $\begin{array}{l}-0.10^{*} \\
(-1.90)\end{array}$ & $\begin{array}{l}-0.07^{*} \\
(-1.74)\end{array}$ \\
\hline$\Delta$ Family TNA & $\begin{array}{l}-0.07^{*} \\
(-1.76)\end{array}$ & $\begin{array}{l}-0.12^{* * *} \\
(-2.29)\end{array}$ & $\begin{array}{l}-0.07 \\
(-1.13)\end{array}$ & $\begin{array}{l}-0.10^{* * *} \\
(-2.07)\end{array}$ \\
\hline$\Delta$ Total load & $\begin{array}{l}-0.03 \\
(-1.16)\end{array}$ & $\begin{array}{l}-0.02 \\
(-0.62)\end{array}$ & $\begin{array}{l}-0.02 \\
(-0.75)\end{array}$ & $\begin{array}{l}-0.02 \\
(-0.44)\end{array}$ \\
\hline$\Delta 12 \mathrm{~b}-1$ & $\begin{array}{l}-0.08^{*} \\
(-1.76)\end{array}$ & $\begin{array}{l}-0.07 \\
(-0.77)\end{array}$ & $\begin{array}{l}-0.08^{* * *} \\
(-2.01)\end{array}$ & $\begin{array}{l}-0.08^{*} \\
(-1.77)\end{array}$ \\
\hline$\Delta$ Morningstar rating & & & & $\begin{array}{c}0.49^{* * * *} \\
(5.85)\end{array}$ \\
\hline Adjusted $R^{2}$ & 0.19 & 0.20 & 0.20 & 0.18 \\
\hline$N$ & 4,057 & 2,076 & 452 & 1,529 \\
\hline
\end{tabular}

This table reports panel regression estimates relating proxies for target fund flow captured by the copycat fund to the difference in fund characteristics between the target and copycat measured in the period preceding copying commencement. The proxy for captured flow (the dependent variable) is the difference between actual and counterfactual flow for the target fund, both measured over the year following the commencement of copying. Counterfactual flow is estimated via the model described in Table 10 of Online Appendix B which includes variables shown to influence flow in the extant literature. The independent variables are as previously defined.

Standard errors are clustered by fund and each model includes year fixed effects. Significance at the $10 \%, 5 \%$, and $1 \%$ levels is indicated by ${ }^{*}$, ${ }^{* * *}$, and ${ }^{* * *}$, respectively. 
Table 7

\section{Copycat survival}

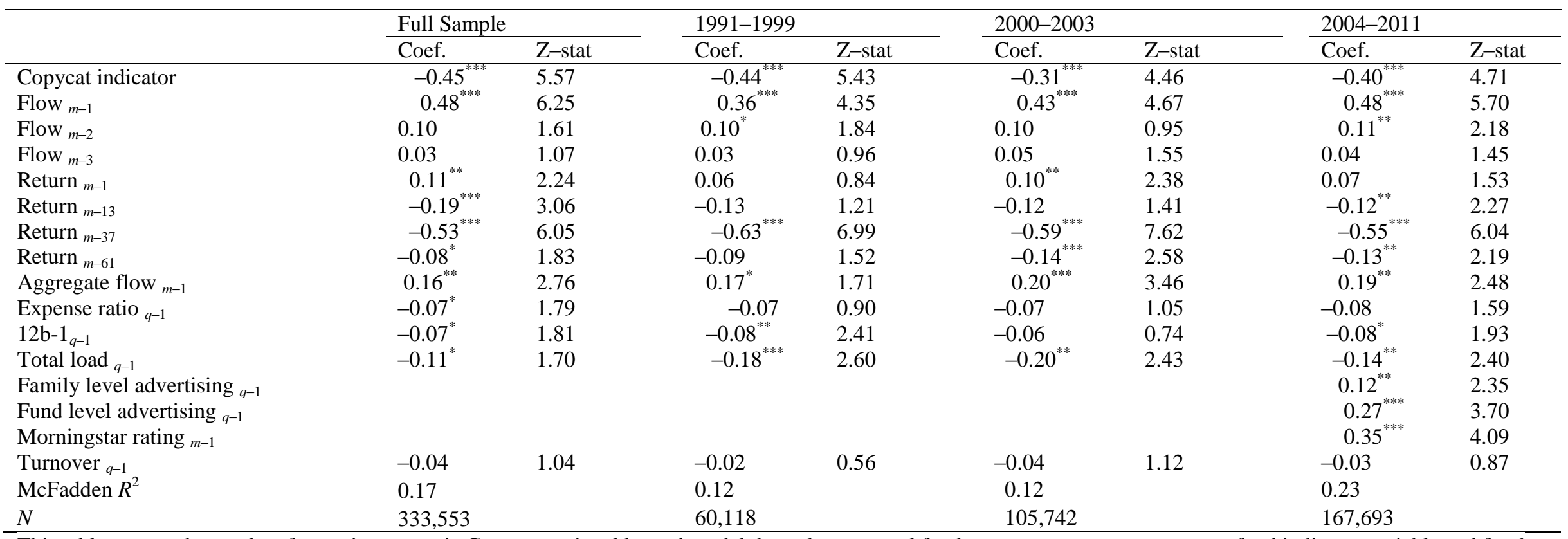

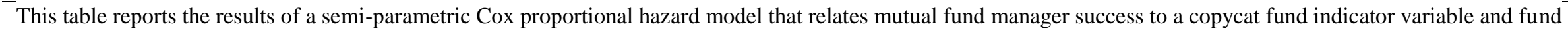
characteristics controls. The sample includes all actively managed, domestic equity funds in the CRSP database. The dependent variable, mutual fund manager success, is measured as the length of time managing the fund. The independent variables are as previously defined with the exception of Copycat, which is an indicator variable set to 1 if the fund is a copycat fund. Z-statistics are reported that are asymptotically normally distributed under the null that the coefficient is equal to zero. The model includes year fixed effects, and standard errors are clustered at the fund level. For ease of interpretation, the coefficients are multiplied by -1 . Hence a positive coefficient value relates to an increased likelihood of the manager continuing to manage the fund. Significance at the $10 \%, 5 \%$, and $1 \%$ levels is indicated by ${ }^{*},{ }^{* *}$, and , respectively. 


\section{Figure 1}

\section{Copycat equalization}

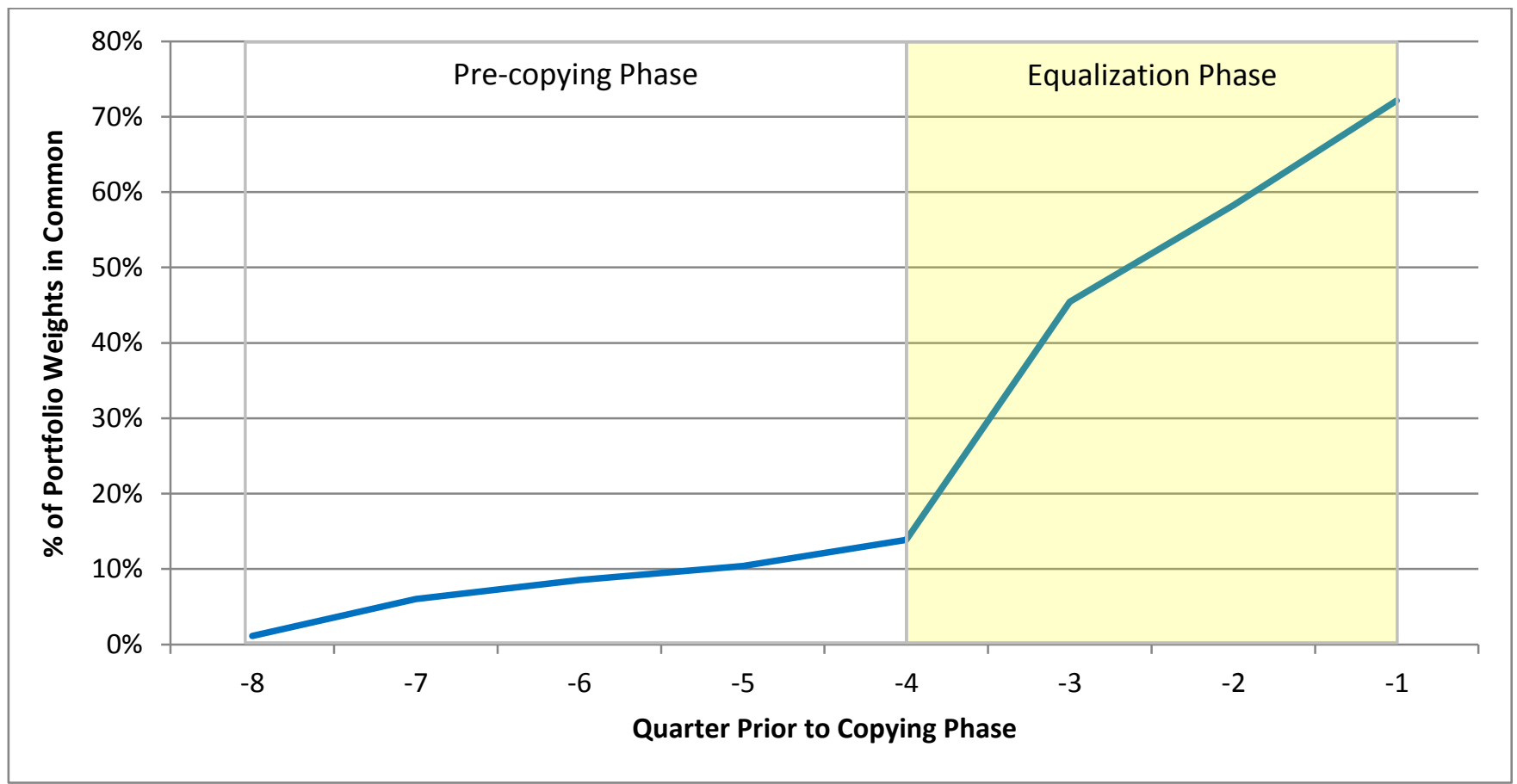

This figure reports the percentage of portfolio weights in common between the copycat and target fund in the two years preceding the copying phase. The copycat sample is formed using a minimum trading commonality of $75 \%$ for the $2004-$ 2013 sample period as described in Table 1. 
Figure 2

Target and copycat fund performance by year

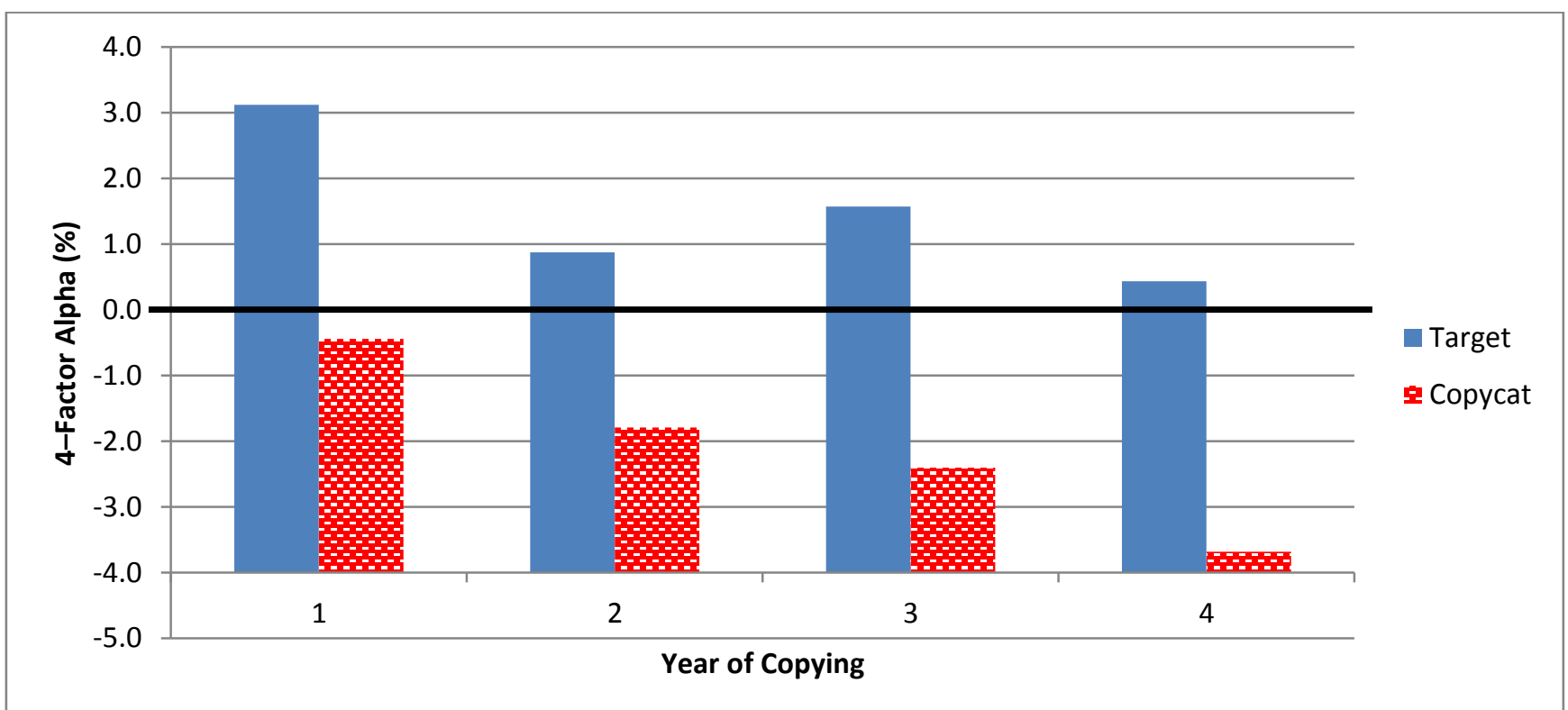

This figure summarizes average performance for the target and copycat funds by year of copying. Performance is calculated using the Fama and French (1993) and Carhart (1997) four-factor model. 